\title{
La libertad en Paul Ricoeur
}

\author{
HACIA UNA LIBERTAD CONCRETA *
}

\subsection{El método}

El pensamiento de Paul Ricoeur aparece como una encrucijada de caminos filosóficos por lo que algunos de sus críticos no dudan en hablar de sincretismo y ausencia de rigor científico ${ }^{1}$. Evidentemente Ricoeur tiene tras sí su enseñanza de la Historia de la Filosofía, pero precisamente por ello parece necesario considerar estas palabras: «Y más allá de todos sus escritos, noś atre-

\footnotetext{
* SIGLAS U III.IZADAS

KE P. Ricoeur -M. Dufrenne, Karl Jaspers et la philosophie de l'existence. Seuil, Paris 1947.

VI P. Riconur, Philosophie de la volonté. I: Le volontaire et l'involuntaire. AubierMontaigne, Baris 1967.

HF P. Ricoeur, Phillosophie de la volonté. II-I: L’homme faillible. Aubier-Montaigne, Paris 1968.

SM P. RICOEUR, Philosophie de la volonté. II-II: La symbolique du mal. AubierMontaigne. Paris 1960.

HV P. Ricoeur, Histoire et vérité. Seuil, Paris $1964^{3}$.

DI P. Ricoeur, De l'interprétation. Essai sur Freud. Seuil, Paris 1965.

CI P. Ricoeur, Le conflit des interprétations. Essais d'herméneutique. Seuil, Paris 1969.

MV P. Ricoeur, La Métaphore vive. Seuil, Paris 1975.

PSE P. RICOEUR, Political and Social Essays. Edited by David Stewart and Joseph Bien. Ohio University Press, Athens 1976.

AF Archivio di Filosofia.

$P \quad$ Pensamiento.

PhF Phänomenologische Forschungen.

PhT Philosophy Today.

RPhL Revue Philosophique de Louvain.

RPhT Revue de Théologie et de Philosophie.
}

1. P. Thuillier, Socrate fonctionnaire. Essai pour (et contre) ta philosophie universitaire. Paris 1970, 138: «Ni M. Lévinas, ni M. Ricoeur, ni M. Jankélevitch, en tout cas, ne sont des mâ̂tres en matière de strenge Wissenschaft, de science rigoureuse». 
veríamos a decir que la razón última de toda su obra se encuentra en la honradez y respeto de Ricoeur con los demás y en la fidelidad a su espíritu no feudatario de intereses o particularismos de ningún tipo» ${ }^{2}$.

Las influencias de otros no pueden negarse; pocas veces abandonó completamente Ricoeur sus fuentes ni se sometió a ellas de forma servil. Más bien hace su propio camino apoyado en todos sus predecesores, sobre cuyos hombros busca un nuevo horizonte. En su obra quedan, como se verá, los temas kantianos de la trascendencia y la libertad, heredados a través de Lachelier y Jaspers. El cogito cartesiano sometido a nuevas pruebas por los maestros de la suspicacia: Marx, Freud y Nietzsche. El yo ideal fichteano y la egología husserliana confrontada, más allá del empirismo y del idealismo, al socratismo esperanzado pero existencialista de Marcel y el realismo idealista de Nabert ${ }^{3}$.

La libertad geométrica de Spinoza se hace carne en la filosofía de la voluntad de M. de Biran, Ravaisson y la corporalidad, elaborada por MerleauPonty. La desesperanza del mal humano queda acogida a la promesa de la cultura post-cristiana, el empuje de Claudel, y la filosofía de la acción de Blondel recibidos críticamente en Ricoeur. Por toḍo ello Ricoeur no puede ser ecléctico pues no es un escéptico: «A la limite l'historien 'sceptique' ne cherche plus rien, la philosophie 'dogmatique' n'a plus que des ennemies ou élevès mais non point d'amis» ${ }^{4}$.

Esto será menos posible aún porque la influencia de E. Mounier imprimirá un espíritu especial al pensamiento de Ricoeur: «Cette manière de lier la réflexion philosophique en apparence le plus éloignée de l'actualité aux problèmes vivants de notre temps, ce refus de dissocier una critériologie de la véritè d'une pédagogie politique, ce goût de ne pas separer le 'réveil de la personne' de la 'révolution communitaire', ce regus de verser dans le préjugé antitechniciste sous prétextes d'interiorité, cette méfiance pour le 'purisme' et le catastrophisme, cet 'optimisme tragique' enfin, toute cela je le nomme ma dette à Emmanuel Mounier» ${ }^{5}$.

2. C. Díaz-M. MACEIRAs, Introducción al personalismo actual. Madrid 1975, 143.

3. J. NABERT, Eléments pour une Ethique. Paris 1963, 34: «Le même conclusion se dégage si l'on examine le retentissement du succès dans les consciences qui en sont les témoins et qui ont quelque peine à se défendre de penser qu'une cause ne pouvait être radicalement mauvaise ou condemnable, qui a été victoriouse dans les compétitions humaines. Chez le vainqueur luimême le succès tend à recréer une bonne conscience, à faire taire les scrupules, et d'autant plus que les choses ou les autres consciences se montrent docils au fait et semblent lui donner comme une ratification. Ce que n'avait pu faire ni le plaidoyer, ni les vertus déployées dans l'effort, les succès l'obtient: il rallie les esprits, il paraît en accord avec un profond qui ne saurait tolérer qu'une entreprise réussit que transgresserait les lois fondamentales de la conscience et de l'être»:

4. $H V, 54$. Según $\mathrm{P}$. Javet, Ricoeur se deja instruir por la tradición filosófica pero prefiere la dialéctica al escepticimo: «Imagination et réalité dans la philosophie de Paul Ricoeur». $R P h T$, 3 (1967) 159-160.

5. $H V, 9$. 
Es en el personalismo donde Ricoeur aprende la libertad concreta y universal: «Nous ne sommes libres que dans la mesure ou nous ne sommes pas entièremente libres (Qu'est-ce que le personnalisme, 26). Ici s'esquisse déjà le type de philosophie de l'existence que le personnalisme privilégie: sa liberté ne sera point gratuite mais nécessité comprise et responsabilité exercée. Cet aperçu sur 'la liberté sous conditions' tourne ici à une critique de l'esprit d'utopie que voudrait élaborer le schéma d'une société et les règles d'une action à partir de principes, sans jamais incorporer à cette recherche la lecture de l'événement, l'exégèse des forces historiques» ${ }^{6}$.

En este cuerpo a cuerpo con la historia y la vida, la existencia humana pierde su ingenuidad fácil y adquiere todo su valor al explicitar sus presupuestos y superar la prueba de la analítica del deseo freudiana, del inconsciente económico de Marx, la astucia del poder nietzscheano y la arqueología del sentido estructuralista: «Neither is the self intuited. The first truth, 'I think, I am', is empty unless it is mediated by representations which 'objectivize' it. Reflection must be concerned with the act of existing, but this act can only be grasped in signs cattered in the world ${ }^{7}$.

A partir de las teorías del lenguaje de Heidegger, toda la obra va a cristalizar en torno a la libertad como horizonte de la comprensión y de la presencia humana: «Nous tenons ici le germe de la philosophie de Paul Ricoeur. Sur l'axe d'une philosophie de la volonté, elle est dans toute son envergure una philosophie de la liberté, une philosophie de l'action»" ${ }^{8}$.

Buscar los caminos de la libertad, en la obra de Ricoeur, como dimensión fundamental del hombre en nuestro mundo es lo que nos proponemos en esta exposición de su filosofía.

En esta tarea nunca olvidamos que: «El filósofo nato del personalismo es Ricoeur, no sólo heredero, sino también creador de la filosofía de la persona, a la que aporta acentos nuevos: psicoanálisis, fenomenología, estructuralismo, filosofía del lenguaje, estudio de los símbolos, todo ello sin eclecticismo, antes al contrario con tanta fecundidad, que podríamos considerar su filosofía como una ontogénesis de la contemporánea que ninguna historia de las ideas puede olvidar» ${ }^{8 \mathrm{a}}$.

En el fondo, el aparente eclecticismo de Ricoeur, responde a una importante demanda de Mounier; «La psychologie française ne sortira de son som-

6. $H V, 148$.

7. J. D. Stewart, «Paul Ricoeur's Phenomenology of Evil». PhT, 9 (1969) 578.

8. M. Philibert, Paul Ricoeur ou la liberté selon l'espérance. Paris 1971, 43. Subrayado mío.

8a. C. DIAZ-M. MACEIRAS, Introducción, 10. 
meil que le jour où elle se décidera à franchir le Rubicon qu'elle maintient entre le 'subjectif' et 'l'objectif'» 9 .

Como lo insinúa, de otro modo, Ricoeur: «L'empirisme est un discours en 'il y a'. Inversement la connaissance de la subjectivité ne se réduit pas plus à l'introspection que la psychologie empirique ne se réduit à la psychologie de comportement. Son essence est de respecter l'originalité du Cogito comme faisceau des actes intentionnels d'un sujet. Mais ce sujet c'est moi et toi» ${ }^{10}$. La reflexión no puede dejar al hombre convertido en un mero objeto: «En consecuencia, es menester completarlo y, después de haber considerado al hombre como un objeto, tratarlo como un sujeto; remontarse en él, más allá de todas las manifestaciones de la conciencia hasta la conciencia misma, en cuanto está en acto, para estudiar en ella — según la frase de Lachelier- 'la luz en su fuente'» ${ }^{11}$.

Ello no debe hacer pensar que Ricoeur se queda en la reflexión abstracta. En esto sigue a Nabert frente a Lachelier. Igualmente supera, Ricoeur, a M. de Biran incapaz de categorizar teóricamente la acción. Así se acerca a Spinoza en la conciencia de que ambos métodos deben complementarse ${ }^{12}$.

Para Ricoeur el idẹalismo de la trasparencia del Cogito es un titanismo filosófico que se ignora y acaba en un existencialismo negro ${ }^{13}$. Por eso discrepa Ricoeur de Sartre mientras cita a Giraudoux como invitación a estar firmes en la claridad y pacientes en la obscuridad ${ }^{14}$, para conseguir borrar las falsas evidencias y llegar a la libertad ${ }^{15}$. Tal es la aventura del hombre, su libertad: «...puesto que la libertad es una categoría única respecto del mundo y la trascendencia. De la naturaleza el hombre está, en consecuencia, obligado a 'deducir' su ser libre (no individualista sino comunitariamente), evitando el desliz hacia el mundo de lo impersonal y anónimo, eludiendo su objetivación, manteniéndose siempre como sujeto» ${ }^{16}$.

Ese hombre libre es indudablemente el centro de la filosofía de Ricoeur como antropología filosófica que tiende a reconciliar la universalidad y la objetividad con la individualidad y la finitud. El hombre es así mediación espon-

9. M. Mounier, Traité du caractère. Paris 1947,11 . También C. DÍAZ-M. MACEIRAS, Introducción, 31.

10. VI, 14 .

11. A. MARC, Psychologie réflexive. Trad. castellana de A. Puigcerver. Madrid 1965, II, 487-488.

12. J. NABert, Eléments, Preface de P. Ricoeur, 9. Y CI, 212.

13. VI, $436,438$.

14. VI, 383-384.

15. CI, 241. F. D. VANSINA, «La problemátique épocale chez P. Ricoeur et l'existentialisme». $R P h L, 70$ (1972). Con ayuda del método reflexivo e inspirado por J. Nabert, Ricoeur, espera encontrar «les requêtes immanentes de la liberté dans son aspiration à s'égeler a soi-même».

16. C. DíaZ-M. MaCEIRAS, Introducción, 241. 
tánea y tensa entre la infinitud de su conocer o actuar y.la finitud trabajosa de su existencia actual. Tal es la obra en construcción de la libertad ${ }^{17}$. Ricoeur trata de sorprender al hombre en su originalidad previa a toda división sujetoobjeto, y no es independiente de esta orientación el tratamiento aplicado por Ricoeur a los hallazgos de Freud y Marx. Tal intención califica para siempre su propio camino. Su metodología no va a dividir sino a unir, por eso la acusación de eclecticismo evidencia por qué con la misma fuerza se opone a la totalización violenta ${ }^{18}$. Así se crea un espacio abierto a la comunicación en la historia humana, que si es total, será el surgir de la verdad y la libertad ${ }^{19}$.

Propone Ricoeur una reconciliación total por una restauración esperanzada del hombre, al recuperar pasado y relanzar el futuro desde el corazón de la libertad ${ }^{20}$. De este modo: «El que lee a Ricoeur puede experimentar que su obra discurre por los cauces de la mayor serenidad espiritual, aliada siempre con la más exigente radicalidad. Precisamente por estas características podrá significar una alternativa decisiva para muchos de los aludidos sistemas filosóficos o para el pensamiento en general: o la fidelidad al hombre integral o la muerte y la superación forzosa» ${ }^{21}$.

\subsection{El punto de partida de la filosofía: atención y reflexión}

La atención a las cosas suscita el respeto y el reconocimiento de la diversidad propia. Por ello: «El interés de la obra de Ricoeur reside, a nuestro juicio, en que no sólo realiza una meditación integral sobre el hombre y el ser, sino que esboza ya los primeros principios y las teorías que justifican y dirigen aquella meditación. Y esto sin caer en ninguna pretendida sistematización filosófica» ${ }^{22}$.

Con ese estudio fenomenológico de la atención, respetuosa por encima de las presiones del instinto del orden, comenzará la obra de Ricoeur ${ }^{23}$. Así se permite a la realidad presentarse con entera libertad, pues según el aforismo de Claudel, «tampoco lo peor es seguro»; de este modo, quedamos embarcados en una filosofía no constrictiva, desenrejada, con un campo abierto a la

17. S. HACKETT, «Philosophical objetivity and existential involvement in the methodology of Paul Ricoeur». International Philosophical Quaterly, 9 (1969), 1) 11-12. I. KANT, Anweisung zur Menschen und Weltkenntniss. Leipzig 1831, 7.

18. $H V, 165$.

19. $H V, 32$. R. VAlls Plana, Del yo al nosotros. Lectura de la Fenomenología del espíritu. Barcelona 1971.

20. $H F, 16$.

21. M. SANTOS, «La 'Repetición' del mito». Introducción al pensamiento de Paul Ricoeur. Stromata, 27 (1971) 513.

22. M. SANTOS, Ibidem, 511.

23. M. Philibert, Paul Ricoeur, 189. 
poesía creativa ${ }^{24}$. Los símbolos permanecen indicativos invitando a la reflexión. Está, según la tradición kantiana recibida por Ricoeur, recoge sus ofrecimientos y trata de establecer los presupuestos o condiciones de su posibilidad.

Pero a Ricoeur además del nivel estrictamente epistemológico le preocupan el apriori afectivo y práctico. Por ello es preciso ir más allá de las perspectivas particulares a la dimensión estructural, incluso si el pensador reconoce que la actividad práctica humana, no permite, en el mejor de los casos, sino una aproximación a la verdad definitiva, o la construcción de una arquitectónica móvil, o una organización dinámica. Así el antiguo poder infinito de la reflexión queda reducido a sus límites humanos. Tales límites se transforman en fronteras abiertas al incorporar a la reflexión, como una recuperación del hombre, la libertad teórica y práctica «theorical and practical freedom which can reasonably be predicated of human existence» 25 .

La reflexión no puede ser entonces pura abstracción, únicamente theorema', sino que ha de ser 'poiesis' (Lledó). Aquí Ricoeur recoge la herencia de Dilthey: La reflexión es ciega si no se mediatiza por las expresiones en las que la vida se objetiviza ${ }^{26}$. Sólo entonces se alcanza la totalidad đel hombre en las auténticas perspectivas de la libertad ${ }^{27}$; pero se obliga a una dialéctica más allá de todo eclecticismo. La vida rompe el círculo encantado de la propia y exclusiva conciencia, y el privilegio de la reflexión solipsista. Tal es la tradición que atravesando a Kant y Husserl marcha junto a Merleau-Ponty, Nabert, Jaspers, Marcel, Heidegger y Mounier.

De este modo Ricoeur propugna una filosofía que escucha y respeta más allá de la alternativa sumisión-rebelión. Para ello se verá precisado a eliminar el imperialismo 'divino' involucrado en el formalismo de Kant y el espírítu del sistema hegeliano donde todo se arregla demasiado fácilmente para que no sea necesario ir a la sospecha de que el espíritu tan altamente proclamado sea algo más que «una passione mascherata» ${ }^{28}$.

Para entonces, la reflexión o se queda petrificada en la inmediătez empírica o pierde todo contacto con la realidad y deviene un despotismo ilustrado de la consciencia, tanto más despótico cuanto más ilustrado. En ese caso, la reflexión y la consciencia pierden su fianza, aparecen como la reflexión segunda y enmascarada del deseo, y la filosofía se convierte en un disfraz de los intereses - también llamados tecnologías-dominantes.

24. J. D. STEWART, «Paul Ricoeur», PhT, 9 (1969) 132.

25. S. HACKETT, «Philosophical», International Philosophical Quaterly, 9 (1969) 30-31.

26. M. MACEIRAS, «Paul Ricoeur: Una ontología militante». P, 126 (1976) 132.

27. F. D. VANSINA, «La problématique», $R P h L, 70$ (1972) 619.

28. M. CRISTALDI, «La testimonianza delle maschere. Nota sulla critica ermeneutice di Paul Ricoeur». $A F, 3$ (1972) 77 y 84. 
La consciencia deja de ser conocida para ser ella problemática, y es necesario iniciar una genealogía de la reflexión que lleva a una segunda revolución copernicana en la cual esa reflexión, descentrada por fin, sólo puede recuperarse auténticamente contrastada frente a sus actos y a sus obras ${ }^{29}$ con diversas perspectivas. Tal es el sentido del reencuentro de las distintas filosofías y los divergentes procesos de praxis. No se trata de un diálogo de muertos, ni de sublimar las contradicciones, sino de rehacer al hombre por uná filosofía vivida como comunicación total con las realidades.

Pero el primer paso para reconstruir es no incurrir en mutilaciones por un método impuesto a la fuerza, por esto no nos parece del todo exacta la acusación del P. Thuillier al 'método reflexivo' de reservarse el derecho de aceptar todas las interpretaciones que quiera ${ }^{30}$. Más bien se diría que: «La aventura que es el hombre nos aparece con frecuencia bajo las formas más insospechadas y - por encima de todas ellas - la labor indispensable es hacer que él sea cada vez más libre, más 'por sí', puesto que la libertad es una categoría única reśpecto al mundo y la trascendencia» ${ }^{31}$.

Y ello porque como bien ha visto G. Gusdorf: «Or la liberté n'est pas un objet, que l'on pourrait s'apropier une fois pour toutes, de telle sorte qu'il serait inutile d'y repenser par la suite» ${ }^{32}$. Pues la libertad no es un atributo que deje al hombre tan determinado o indeterminado como el ser bípedo, mamífero o no pescado.

La libertad es la llamada humana que inicia un compromiso de realización y precisa investigar sus condiciones de posibilidad y desarrollo sin darlo por evidente: «Yet Ricoeur is basically critical of Hegel's actual performance in carrying out his phenomenological analysis: he rejects Hegel's ideal of pure self-reflection as an adequate basis for total understanding of man's being and he insist that the self is not inmediately apprehended as a starting for thought but is only apprehended progressively in its acts and operations as correlated with the world that the self confronts» ${ }^{33}$.

Ricoeur se niega a empalarse en los cuernos del dualismo que establece el abismo entre la objetividad válida universalmente y la subjetividad como pura reflexión, pues auto-conciencia y mundo sólo puede entenderse como correlación mediada por el propio cuerpo. La reflexión pura no es por sí misma evidente ni puede tomarse como punto de partida de la filosofía. No es algo claro

29. E. RENZI, «Freud e Ricoeur». Aut, Aut, 98 (1967) 14.

30. P. THUILLIER, Socrate fonctionnaire, 183.

31. C. DÍAZ-M. MACEIRAS, Introducción, 241. Subrayado mío.

32. G. GuSDORF, Signification Humaine de la Liberté. Paris, 1962, 263.

33. S. HACKETT, «Philosophical», International Philosophical Quaterly, 9 (1969) 13. Subrayado mío. 
sino vago, necesitado de ser probado en actos, instituciones y realizaciones ${ }^{34}$; el hombre no es una esencia clara y distinta sino como una esencia en trance de clarificación y realización. Tal es la confusión de la filosofía intelectualista.

El problema de la condición humana, del hombre concreto, apunta hacia algo común, pero de naturaleza única, un universal concreto: «Seule la philosophie de la liberté concrète, de l'individu en situation, permet de le poser correctement...» ${ }^{35}$. Es preciso repensar la. objetividad en la libertad por un proceso de restauración. El verdadero método reflexivo no es solamente descripción sino reapropiación: "La philosophie réflexive peut dire 'qu'elle s'annexe la pensée symbolique et les relations multiples entre les intentions significatrices et les modes signifiants': elle vise a faire coïncider ultimement la comprèhension de soi, sur la base du 'texte que ces actions ont constitué' (Eléments pour une Eyhique, 3) avec «une régéneration de son être» (Ibid.)» ${ }^{36}$.

Este método inclusivo del apriori y el aposteriori, empírico, se aleja de la exclusividad epistemológica de la lectura de Kant y se acerca a Spinoza por una reflexión de la praxis; deja atrás a Lachelier y evita el irracionalismo de M. de Biran.

De este modo, se revalidan simultáneamente la teoría y la praxis, se construye una auténtica filosofía, porque: «Fundamentar filosóficamente es construir y mostrar la relación de toda representación teórica y de toda actividad práctica con el campo de las razones fundamentales a las cuales la filosofía tiene acceso en su avance y su representación» ${ }^{37}$. En otro caso, la objetividad carece de sentido y el sentido pierde a su vez los objetos, se mueve en el vacío.

Si bien es verdad que «Sólo la teoría decide acerca de lo que se puede observar» ${ }^{38}$ y que como ha dicho G. Canguilhem «le fait scientifique c'est ce que la science fait en se faisant» ${ }^{39}$, no lo es menos que la realidad ofrece a la codificación su propia resistencia, su particular especificidad frente a la «inteligencia asimilante» ${ }^{40}$. La peligrosidad de tal inteligencia ha sido certeramente señalada por Foucault: «Superficialmente, podría decirse que el conocimiento del hombre, a diferencia de las ciencias de la naturaleza, está siempre ligado, aun en su forma más indecisa, a la ética o a la política; más fundamentalmen-

\footnotetext{
34. S. HACKETT, Ibidem, 15.

35. KE, 341 y 342 . Subrayado mío.

36. J. NABERT, Eléments, 13. Subrayado mío.

37. M. GODELIER, Rationalité et irrationalité en économie. Trad. castellana de N. Blanc, S. XXI Mexico, 19744a, 115.

38. Aseveración de Einstein citada por P. LAIN ENTRALGO, «La praxis marxista». II, Gaceta Ilustrada, 1083 (1977) 19. Para un desarrollo más científico pueden verse: T. Kuhn, Feyerabend y K. Popper.

39. Citado por $H V, 25$.

40. $H V, 30$.
} 
te, el pensamiento moderno avanza en esta dirección en la que el Otro del hombre debe convertirse en el Mismo que él» ${ }^{41}$.

La resistencia de la praxis humana se encamina a la trasformación y por fin a la victoria de una «buena subjetividad sobre una mala subjetividad», la subjetividad abierta a lo inesperado, a lo distinto, a lo otro ${ }^{42}$. Así es como por mí mismo, y más allá de mí mismo compruebo «l'être homme» ${ }^{43}$. El cuerpo propio es la primera forma de resistencia al proceso asimilante, frente a la idealización y contra la cosificación. Pues la subjetividad humana es simultáneamente 'interna' y 'externa' ${ }^{44}$ sin ruptura posible, a menos que deje de serlo, porque: «Le corps comme corps d'un sujet et le corps comme objet empirique ne coincïden pas» ${ }^{45}$.

Como consecuencia, el campo de la libertad no se encuentra ni en el dominio de la cosificación ni en una desencarnación ideal ${ }^{46}$. En esta situación Ricoeur va a trasgredir a Descartes: «Toute notre analyse tendre au contraire (de Descartes) à montrer les liens de la conscience au et non l'insularité d'une conscience qui se retire en elle-même» ${ }^{47}$. Entonces la reflexión tematiza una afirmación práxica pre-reflexiva, militante (agissante) y no espectacular ${ }^{48}$.

Ahora, la atención, esclava por los interesès, la sistematización, y la asociación rígida, se vuelve atención libre. Atender es liberar lo atendido, por eso la mayor receptividad es la mayor actividad, lo opuesto a la fascinación y el determinismo. La atención clarifica la encarnación, la confusión corpórea y la afectividad ${ }^{49}$. Como escribía León Felipe: «Cuando el hombre doméstico, egoísta y tramposo, degrada" el mundo y todo lo rebaja, cuando las cosas no son lo que deben ser, lo que pueden ser, el mecanismo metafórico del poeta es el primer revolucionario. Y antes denuncia nuestras miserias el poeta que el moralista» ${ }^{50}$.

Por otra parte, de este modo es posible recibir la vida misma de lo involuntario en el corazón de la libertad y descubrir que la reflexión abstracta es segunda con respecto a la ingenuidad primordial de la libertad, que no es la eterna indiferencia de poder elegir, pues ésta, según Nietzsche, es la enfermedad del ser que lo corrompe al arrancarlo a la praxis ${ }^{51}$.

41.. M. Foucault, Les mots et les choses. Trad. castellana de E. C. Frost. México 19713a, 319. Cfr. a nivel ético: X. Rubert De Ventos, Moral y nueva cultura. Madrid, 1971.

42. $H V, 33$.

43. $H V, 36$

44. VI, 14. J. Llovet, Por una estética egoísta. Esquizosemia. Barcelona 1978.

45. $V I, 15$.

46. $V I, 16$ y 19.

47. $V I, 42$.

48. $V I, 58$ у 59 .

49. VI, 148, 149 у 178.

50. Citado por S. Genoves, El mono inquisitivo. Barcelona 1973, 131.

51. $V I, 179,180$. 
La atención nos mantiene despiertos, abiertos al mundo de un modo personalizado y desprendido, universal y concreto. La vida es un involuntario absoluto que me da el existir como consciencia, y un voluntario relativo que me pide mi decisión y mi esfuerzo ${ }^{52}$. En el corazón de la libertad el discurso lineal representa la causalidad total determinada mientras que la atención reflexiva presenta la discontinuidad ${ }^{53}$.

La antropología filosófica procede de la elucidación de la realidad global a partir de la totalidad dada pre-filosóficamente y comprendida, en cierto modo, antes que reflexionada: «Nous sommes ainsi conduits plus près d'une hypothèse de travail articulée par cette idée d'une différence de potentiel entre una précompréhension non philosophique et un commencement méthodique de l'élucidation» ${ }^{54}$.

Esta comprensión ocurre dentro de una cultura y una consciencia, por eso es preciso romper el círculo encantado de la reflexión primera y la comprensión inmediata, hacia la profundización de la simbólica. Esta lleva en sí la revolución copernicana porque coloca lo particular en la totalidad. Así, el hombre debe elaborar estructuras de reflexión pero sobre todo estructuras de existencia, en tanto que la existencia es el ser del hombre ${ }^{55}$. Desde la situación se va a la racionalidad de sus fundamentos.

Así una filosofía reflexiva es lo contrario de una filosofía inmediata, el hombre debe recuperarse en sus obras; por tanto, debe contar con todos los resultados, presupuestos y métodos de las ciencias que intentan descifrar los signos del hombre. Con Fichte y Nabert puede decirse que, la reflexión es menos una justificación de la ciencia y del deber que una reapropiación de nuestro esfuerzo por existir ${ }^{56}$. Con ello se continúa también un temảa fundamental de Spinoza.

La reflexión abstracta toma carne en la realidad vital como oyente de la palabra, atenta a todo signo de la totalidad vital; así su ingenuidad primera se vuelve docta. La resistencia de la realidad impide a la reflexión cerrarse sobre sí misma, y al perderse se recupera. Su morir indica una ontología; al desplegar una arqueología y una teleología reconcilia las interpretaciones discordantes ${ }^{57}$.

52. VI, 394.

53. $H F, 16$.

54. $H F, 24$.

55. $S M, 332$.

56. $D I, 52,54$. Y $C I, 21$ : «La réflexion est une intuition aveugle si elle n'est point médiatisée par ce que Dilthey appelait les expressions dans lesquelles la vie s'objective. Pour employer une autre langage, celui de Jean Nabert, la reflexion ne saurait être que l'appropiation de notre acte d'exister, par le moyen d'une critique appliqué aux oeuvres et aux actes qui sont les signes de cet acte d'exister".

57. CI, 27: «Dans la dialectique de l'archéologie, de la téléologie et de l'eschatologie, une 
La reflexión concreta es descentración de la consciencia tanto por el lado arqueológico como por lo teleológico. Establece la relación entre lo que Freud llama inconsciente y Hegel espíritu; entre regresión y progresión, entre destino e historia. Ricoeur se detiene en el umbral de las interpretaciones pero en la idea de que sin la dialéctica arqueología-teología no hay solución sino componendas ${ }^{58}$. Se afirma una ontología militante y quebrada frente al totalitarismo.

La libertad lo es en precario; el hombre, más que ser libre en su esencia abstracta, implica un proceso de liberación para construirse como tal. Es necesaria una solidaridad complementaria entre conocimiento verdadero y acción libre, para superar tanto la antinomia kantiana entre libertad noumenal y causalidad empírica, como la oposición bergsoniana entre la 'durée' y el 'moi superficiel', a fin de que la filosofía deje de oscilar entre una libertad exiliada, y una explicación empírica fiel únicamente a la ley de la representación ${ }^{59}$.

Se precisa una reconciliación para evitar que la división entre conocimiento y acción penetre en la consciencia como capacidad para ponerse por una parte y producción laboris isd por otra; de ahí se seguirá una complementariedad entre libertad y normas como lo intenta Nabert ${ }^{60}$; de paso se evita el. dualismo sujeto-objeto, subjetividad-universalización, o la idealización solipsista, para llegar a la naturaleza del hombre de modo parecido a como en Spinoza se van perdiendo las falsas evidencias del libre albedrío y se llega a la libertad. Tal es la tarea de una filosofía reflexiva futura, la reflexión crítica total, superadas las formas patológicas de subjetivismo, por la contrastación de la reflexión con la hermenéutica ${ }^{61}$.

Con una arqueología del sujeto, el pensamiento reflexivo se integra al discurso de su propia arqueología, y así deviene reflexión concreta. Con la teleología, el resultado del análisis arqueológico busca su horizonte de comprensión total. En esta dialéctica la reflexión supera abstracción y se hace concreta, es decir, completa. Tarea difícil pero necesaria paråque el pensamiento alcance la realidad, lo concreto. Simultáneamente se levanta la caución que la epistemología kantiana impone a la praxis; maleándola. También para el maestró Gadamer la hermenéutica es algo más que epistemología: «Se ha dicho que la hermenéutica se orienta sólo al entendimiento y al acuerdo (Ein-

structure ontologique s'annonce, suscèptible de rassembler les interprétations discordantes au plan linguistique». CI 28; «C'est en développant une archéologie, une téléologie, et une eschatologie que la réflexion se supprime elle-même comme réflexion».

58. $C I, 175,177$.

59. $C I, 214,216$.

60. CI, 216,217 y $D I, 334,335$.

61. CI, 241, 292. 
verständnis) y que por eso infravalora la función crítica que nuestra razón ha de asumir en el contexto social. Pienso que esto es falso. Todo proceso de entendimiento (Verständigung) sobre algo implica una comprobación crítica, y no hay mejor crítico de los propios prejuicios que la discusión (Auseinandersetzung) sobre problemas reales que se lleve a cabo con espíritu objetivo (e.d. de objetividad). La hermenéutica enseña precisamente que todo crítico resulta criticado en el proceso vital del acontecimiento o realización dialógica en el que descansa y se funda todo discurso (Rede)» ${ }^{62}$.

Tal es el paso de una libertad cartesiana a otra de tipo spinozista, con una liberación de las naturalezas, sin moralismos, a través de la realidad misma que reconcilia el eros y el deseo ${ }^{63}$.

\subsection{La remodelación - aceptación y superación-de la Fenomenología}

El método fenomenológico también pretende superar una ingenuidad; el sentido común de «lo natural es»... ${ }^{64}$. Ricoeur ha aprendido este camino de Husserl y Jaspers para rehacer al hombre más allá de las ideas y de las cosas, según el talante existencialista que, tras asumir èl pasado, erosiona la oposición libertad-objetividad ${ }^{65}$. El existencialismo sería precisamente la reacción de la filosofía del hombre a la filosofía de las idęas y de las cosas. El personalismo de Ricoeur se siente familiar de muchos temas existencialistas ${ }^{66}$ y el diálogo socrático. Frente a las crispaciones de la consciencia intelectualista se busca al hombre.

De entrada, una subjetividad común funda la homogeneidad de las estructuras voluntarias e involuntarias del hombre. El cogito padece y reina por el cuerpo como fuente de motivos, necesidades y poderes ${ }^{67}$. En la aproximación fenomenológica la libertad supera la objetividad mostrenca, pero sin desencarnarse. Para ello acoge la espontaneidad nutricia como fuerza que rompe el círculo encantado del moi, a fin de construir una objetividad superior

62. Declaraciones de Gadamer a A. OrTIZ OSES, Mundo, hombre y lenguaje crítico. Salamanca $1975,10-11$.

63. P. Ricoeur, «Démythiser l'accussation». $A F$ (Demitizzazione e morale) (1965) 73 y 74.

64. E. HuSSERL, Idées directrices pour une Phénoménologie. Traduction et notes par Paul Ricoeur. Paris 1950. E. FinK, «Philosophie als Ueberwindung der 'Naivität'. Nähe und Distanz. Phaenomenologische Vortraege und Aufsätz. Muenchen 1976, 98-126.

65. P. RICOEUR, $K E, 339$ y 349: «On peut se demander pourtant si le génie de la philosophie existentielle n'est pas d'elaborer une nouvelle logique qui engloberait celle de l'Ecole, celle de Kant et celle de Hegel, et donnerait droit de cité, sur le terrain même de l'objectivité, aux structures paradoxales de l'énoncé dont Kierkegaard a pressentie la fécondité. Peut-être que cet effort impliquerait que l'on portâit un intéret specifique aux contenues de l'affirmation et à ses critères propres et remettrait en question le postulat qui oppose liberté et objectivité». Subrayado mío.

66. $H V, 157,158$.

67. $V I, 13$. 
por una dialéctica entre lo voluntario y lo involuntario. Es la participación activa en la propia encarnación como misterio donde la pura descripción husserliana queda superada según el método de G. Marcel: la eclosión del pensamiento por el objeto transforma la objetividad-corporal en existencia ${ }^{68}$.

Mientras la fenomenología husserliana no escapó nunca al peligro encubierto de una desencarnación idealizada, y así mantiene disimuladamente la convicción de envolver la conciencia en sí misma con una pérdida solapada del ser, por el contrario: «Participer au mystère de l'existence incarnée 'c'est adopter le rythme intérieur d'un drame» ${ }^{69}$. Más allá del mero entendimento la vida es polémica, lucha, militancia.

Solamente así es posible la reconciliación lúcida con el mundo por la restauracióh del hombre desde elpacto originario entre la consciencia y la corporalidad. Qúeda así abierta la esperanza de afrontar el conflicto libertadnecesidad inexorable, aunque, por el momento, en precario, con una ontología paradójica que recoge el hiatus entre el método descriptivo p̉uro y la poética de la libertad como sintomatología de la ruptura entre cuanto es y domina frente a lo posible y ahora marginado por la mala fe violenta del sistema revestido de Ego trascendental. La libertad comienza por la deconstrucción de esta aparente inocencia ${ }^{70}$, al lanzar un nuevo proyecto. Ricoeur intentará la nueva alternativa a partir del Lebenswelt husserliano, consciente de que su apuesta hará saltar por los aires precisamente la fenomenología ingenua. Aquí se trata de «'dépasser une eidétique trop claire, jusqu'à élaborer des 'index' du mystère de l'incarnation'» ${ }^{71}$. Es una labor y un esfuerzo en la línea de Spinoza, no de una vana teoría, por el que toda realidad reivindica su valor total y la propia virtud «desde la alienación a la libertad» ${ }^{72}$. Ahora bien, en este «déploiement de l'éffort» no se trata ni de una fuerza superorgánica ni del dominio del cuerpo-objeto ${ }^{73}$.

La teoría gestalista, vgr., Koffka, no soluciona el problema porque conserva la descripción fenomenológica, en un sistema que la revienta ${ }^{74}$. Ricoeur quiere ir más allá, hasta la espontaneidad de lo involuntario, aunque éste lo recibamos en un «savoir-faire preformé» por el cual el hombre hace lo que

68. $V I, 17,18$.

69. VI, 20 у 19.

70. $V I, 33-35$.

71. VI, 204.

72. VI, 205. Cfr. B. SPINOZA, Ethica ordine Geomethrico Demonstrata. Trad. castellana de A. Rodríguez Bachiuller. Madrid 19633a, 299: «El deseo es la esencia misma del hombre (Def. 1 de las Afecciones) es decir (Prop. 7, p. III): un esfuerzo por medio del cual trata el hombre de perseverar en su ser». $D I, 53$.

73. $V I, 205,206$.

74. VI, 209. 
quiere, es libre, pero a partir de un saber hacer espontáneo involuntario ${ }^{75}$. Entonces, incluso el instinto más que determinismo es parlamento decisivo que regula el efecto más que producirlo, y supone de algún modo un sentido, incluso si éste es más bien arqueológico o implicativo de un talante ${ }^{76}$.

De paso, se rechaza también un idealismo que reduce la corporalidad a un mero órgano de la conscieňcia ${ }^{77}$. No basta evitar el irracionalismo, es preciso además no separar la significación de su mundo ${ }^{78}$. El significado, expresado en un lenguaje, habita de algún modo previamente la realidad y por eso el símbolo 'dona lo que dice' ${ }^{79}$, y para descubrirlo hay 'un saber laborioso' que llega a las profundidades de la conciencia inmediata y las hiere en sus ilusiones de evidencia ingenua ${ }^{80}$. En este mismo combate queda tocada la fenomenología.

La fenomenología primera está más próxima a Descartes, mientras que la 'nueva problemática de la libertad' se acerca más al psicoanálisis y a Spinoza ${ }^{81}$. La praxis analítica se distingue de «todos los equivalentes fenomenológicos imaginables» ${ }^{82}$ y señala con el dedo la arqueología que no alcanza el análisis fenomenológico ${ }^{83}$. No cabe ya hacerse ilusiones. En esta 'antropología concreta' se pone en cuestión el estatuto de la representación cosificada para sumergirla en la vida y el esfuerzo ${ }^{84}$ : Comprender no es ya un modo de conocimiento, sino un modo de ser de quien comprende ${ }^{85}$. Husserl destruye la dualidad sujeto-objeto con la Lebenswelt, y el objetivismo científico y psicologista con su escrito Krisis. El primer Husserl acaba en el idealismo, el segundo en la vida: antes del sujeto de la teoría del conocimiento hay la vida en acción ${ }^{86}$. Por eso mismo la translaboración freudiana no puede reducirse a una simple toma de conciencia fenomenológica.

Para Ricoeur, psicoanálisis y estructuralismo coinciden en su ataque a una filosofía del sujeto, y en particular a la fenomenología de Husserl ${ }^{87}$. Con una serenidad implacable nuestro autor va más allá de Merleau-Ponty al aceptar 'la etapa de la ciencia objetiva de los signos' y el sistema autónomo de la

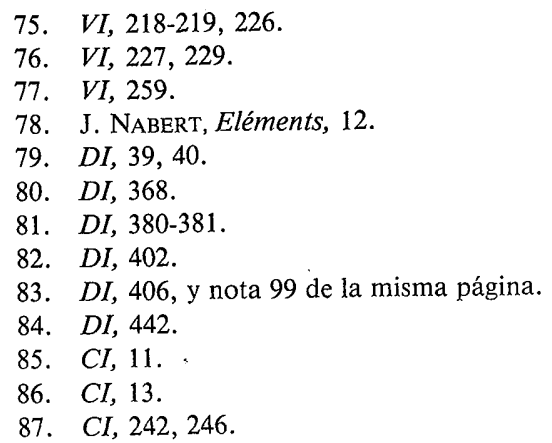


'langue'; algo más que una simple mediación, para no recaer en la vieja psicología del 'habitus' ${ }^{88}$. Se trata de una verdadera descentración de la conciencia por el 'desafío semiológico' de los sistemas taxonómicos ${ }^{89}$. Sólo de este modo es posible intentar posteriormente la convergencia o el paso entre 'semiología' y 'semántica' en un verdadero discurso ${ }^{90}$.

El privilegio concedido a la conciencia en la reducción idealista ès para el estructuralismo «le prejugé absolu de la phénoménologie. Avec cette antinomie, la crise de la philosophie du sujet atteint son point extrême» ${ }^{91}$. Sometida a este juicio de signos por Ricoeur, la reducción deja de ser una operación fantástica y aparece de nuevo, por la 'función simbólica' como la posibilidad 'trascendental del lenguaje' por la que el hombre deja de ser una naturaleza cualquiera entre otras, para llegar a lo real por medio de los signos ${ }^{92}$. Es el nacimiento de la consciencia como diferencia de la Naturaleza, no necesariamente como una egología según demostró ya Sartre ${ }^{93}$. La teoría husserliana del sentido es insuficiente y una «abstracción metafísica» ${ }^{94}$.

Para Ricoeur, la historia de la cultura es la gran «matriz de los signos», mucho más que la «consciencia individual» ${ }^{95}$. Por eso, se enlaza la ruta de la fenomenología del espíritu de Hegel con el análisis freudiano «enraizado en la vida y el deseo'; la fenomenología debe complementarse con una económica y hermenéutica ${ }^{96}$, porque contrariamente a la búsqueda cartesiana y husserliana de una primera verdad, la filosofía parte siempre de un medio humano y un lenguaje concreto dados ${ }^{97}$. No basta entonces utilizar la consciencia directa husserliana y el discurso especulativo, es preciso echar mano de la suspicacia nietzscheana iniciada en el dinamismo de la vida ${ }^{98}$.

- El método se mueve ahora en espiral con diferentes niveles y desarrollos. La nueva hermenéutica de Ricoeur no destruye la fenomenología en cuanto tal, sino su interpretación idealista en el primer Husserl, el abuso de la intui-

\footnotetext{
88. CI, 244, 245, 247, 248.

89. $C I, 247,249$.

90. CI, 248, 250, 251 .

91. CI, 253.

92. CI, 354. Y A. PIntor Ramos, «Paul Ricoeur y el estructuralismo». P, 122 (1975) 86,

93. J. P. SARTRE, La trascendance de l'ego. Paris 1972. CI, 255-256. Y D. NATAL, «Contribución al problema de la libertad en Sartre. A propósito de 'Lẻs mouches'». Estudio Agustiniano, 12 (1977) 579-580.

94. $C I, 392$.

95. $C I, 463$.

96. $C I, 464,486$.

97. P. Ricoeur, «Herméneutique des symboles et réflexion philosophique». $A F, 1-2$ (1961)

98. $M V, 356-357$
} 102. 51-51. 
ción y lo subjetivo, la escisión del sentido y la cosa, etc...; pero fenomenología y hermenéutica se presuponen mutuamente superado el momento idealista ${ }^{99}$.

La libertad implica ahora voluntad y «no-voluntad», con una trasformación cualitativa de la metodología reflexiva: Fundar la consciencia es restaurarla ${ }^{100}$. El método de Husserl, según Ricoeur, es solamente significativo mientras se aplica a objetos que son meras representaciones ${ }^{101}$. Por eso Ricoeur entra, con el rigor de Husserl, en el componente kierkergaardiano de Jaspers y en la filosofía de la corporalidad de Marcel que se dirige a las personas después de las cosas, con su profundidad antropológica irreductible, donde la libertad revela la existencia ${ }^{102}$.

Así, a través de Merleau-Ponty y de Waelhens, la fenomenología se acerca al análisis freudiano remodelado por Ricoeur según una labor de, praxis, y la consciencia husserliana se pone ante la limitación humana sin abandonarla a la irracionalidad ${ }^{103}$. Como nos dirá M. Maceiras: «Su método (de Ricoeur) es noético-noemático, y en él el análisis noemático nos lleva a la comprensión de la nóesis»» ${ }^{104}$. La fenomenología se ve aquí animada y apoyada por una filosofía del lenguaje y, en definitiva, de los signos ${ }^{105}$.

Al principio, Ricoeur no se había introducido totalmente en las posibilidades y dimensiones del conflicto, en la fenomenología del lenguaje y las diversas hermenéuticas ${ }^{106}$. Ricoeur va a mantener la intencionalidad como telos, pero no de un modo fácil, sino con lạ inclusión de una vuelta al origen (Ursprung): «The language toward which he has worked back in his Rückfra$g e$ is that of experience, the language of symbolic expressions» ${ }^{107}$. Así se anuncia ya una arqueología y una teleología.

$\mathrm{El}$ acceso al hombre es en gran parte indirecto, y solamente una verdadera hermenéutica puede conseguir un auténtico desvelarse de la realidad. Entonces el 'conflicto de las interpretaciones' se convierte en desencubrimiento de los diferentes aspectos de la realidad por una reducción sin ilusiones ${ }^{108}$. De

99. P. Ricoeur, «Phénoménologie et herméneutique». PhF, 1 (1975) 31, 32, 33-36 y 75.

100. P. RICOEUR, «From existentialism to the philosophy of language». Criterion, 10 (1971) 153. M. SANTos, «La 'Repetición'». Stromata, 27 (1971) 510, 512. J. D. STEwarT, «Paul Ricoeur», $P h T, 4 / 4$ (1968) 227.

101. J. D. STEWART, Ibidem, 230.

102. J. D. STEWART, Ibidem, 231-233.

103. E. RENZI, «Freud e Ricoeur». Aut. Aut, 98 (1967) 38, 41-43, 45-46. S. HACKETT, «Philosophical», International Philosophical Quaterly, 9 (1969) 14, 38.

104. C. DÍAZ-M. MACEIRAS, Introducción, 150.

105. J. D. STEWART, «Paul Ricoeur», PhT, 9 (1969) 582-583.

106. P. Bourgeors, «Hermeneutics of symbols and philosophical reflection: Paul Ricoeur», PhT, 15 (1971) 232.

107. P. BourgeoIs, Ibidem, 234.

108. P. BOURGEOIS, Ibidem, 235. 
una fenome^ología unívoca se pasa a otra multidimensional. Se trata de saber cómo una filosofía reflexiva puede alimentarse en la fuente de la simbólica y devenir hermenéutica ${ }^{109}$. Se establece una dialéctica entre semántica y reflexión que mira a la existencia y a la ontología.

\subsection{Ontología inacabada: Militante y rota}

Los símbolos invitan a preguntar por el ser del hombre y su posición en el horizonte total de la existencia humana ${ }^{110}$. La filosofía no es ya solamente forma de pensar, sino presencia de ser autocomprendida en sus estructuras dinámicas. Las diversas perspectivas del pensar reflejan las riquezas de la experiencia vivida.

Una ontología se hace comprensible únicamente como reconciliación no fácilmente alcanzada ni violentada por el espíritu de sistema. La esperanza de la convergencia militante no anula la contradicción concreta ${ }^{111}$. Para Ricoeur, la ontología es siempre una tierra prometida, no un dominio definitivamente conquistado. La metafísica queda solamente indicada al final de la peregrinación filosófica, no definitivamente establecida y poseída ${ }^{112}$.

El hombre es precisamente ese luchador que 'agoniza', en el sentido unamuniano, entre su deseo de realización total y sus propias limitaciones. Ricoeur no lo librará de esta 'agonía' con la entrega de su vida a un sistema, a pesar de las extrañezas de S.C. Hackett ${ }^{113}$. Ricoeur no desea ontologizar la falta ni la trascendencia, sino esbozar la arquitectura del proceso de liberación ${ }^{114}$. La ontologización de la falta por Jaspers hace que Ricoeur se vuelva hacia Marcel para buscar una ontología de la reconstrucción, la reconciliación y la esperanza.

La «ontología militante» apunta a una existencia dialéctica entre las realidades condicionantes y sus posibilidades creativas ${ }^{115}$. Se supera así uno de los defectos fundamentales del primer Husserl: su incapacidad para reconocer conceptos limitantes al enfatizar la validez ontológica del objeto en la consciencia con olvido de la crítica kantiana por un lado y la eliminación por otro del valor ontológico del mundo, sea el que sea ${ }^{116}$. Su egología es un cogito sin

109. P. BourgeoIS, Ibidem, 239-241.

110. J. D. StEWART, «Paul Ricoeur», PhT, 9 (1969) 576.

111. J. D. STEWART, Ibidem, 587.

112. P. BourgeoIS, «Hermeneutics», PhT, 4/4 (1971) 232.

113. S. HACKETT, «Philosophical», International Philosophical Quaterly, 9 (1969), 1) $37-$ 39.

114. F. D. VANSINA, «La problématique», $R P h L, 70$ (1972) 594-596.

115. M. MACEIRAS, «Paul Ricoeur», $P, 126$ (1976) 114-5.

116. J. D. STEWART, «Paul Ricoeur», $P h T, 12$ (1968) 228. 
res cogitans; según Ricoeur carece de exterioridad verificante ${ }^{117}$, y así se aparta de la historia, del mundo y del otro ${ }^{118}$.

La nueva ontología es la libertad ${ }^{119}$ en la existencia histórica. El símbolo, aquí funciona como indicador de tal ontología del ser del hombre en el corazón del ser ${ }^{120}$. Entonces la hermenéutica es una «ontología indirecta». Y la restauración del sentido una filosofía de la ilusión al estilo nietzscheano. En este contexto es exacto lo que P. Thuillier cree un reproche: La verdad está muy lejos, detrás y delante de nosotros, muy alta por encima de nosotros ${ }^{121}$.

Simultáneamente Ricoeur 'cuestiona seriamente' el poderoso reduccionismo de la sistemática hegeliana por su falta de respeto a la oposición. La universalidad hegeliana, escamotea la finitud humana ${ }^{122}$. El análisis hegeliano del hombre es insuficiente, prescinde de la concreción y trasforma la libertad en un demiurgo absoluto implacable e inverificable. El proceso de personalización se vuelve imposible y la libertad incorrecta. Lo universal se aleja de lo concreto y termina por eliminarlo.

Por el contrario, según Ricoeur, la singularidad del individuo se encuentra en una acción total de sí sobre sí: la libertad abierta a toda realidad ${ }^{123}$. Por esta apertura la doctrina de las cifras de Jaspers se aproxima al misterio ontológico de Marcel y salva la libertad humana de la destrucción ${ }^{124}$. La libertad concreta, el ser en el mundo y el trascenderse al mundo es esta misma libertad.

La libertad no debe convertirse en una reificación ontológica ni destruir la inefabilidad de su ser en una trascendencia objetivista. Ella es también una cifra ${ }^{125}$. Sólo así es posible articular vitalmente la ruptura a la energía, la finitud al ser, el «Abgrund du néant au Grund de la transcendance» ${ }^{126}$, y organizar la restauración permanente del ser sin caer en el sistema de la Naturaleza o de la trascendencia, pues la libertad es simultáneamente presencia y ausencia reconciliada al mundo ${ }^{127}$, donde el conflicto naturaleza-libertad activado creativamente inicia de sentido la libertad ${ }^{128}$. Esta, desde la situación, va al encuentro de su ser y vive por él ${ }^{129}$.

117. J. D. SteWART, Ibidem, 229.

118. J. D. StEWART, Ibidem, 230.

119. J. D. STEWART, Ibidem, 232-234.

120. $S M, 331$.

121. P. THUILLIER, Socrate fonctionnaire, 113.

122. S. HACKETT, «Philosophical», International Philosophical Quaterly, 9 (1969) 1) notas 17 y 13.

123. - $K E, 343$.

124. $K E, 359,361$.

125. $K E, 362,384-385$.

126. $K E, 370$.

127. $K E$, , 387-388.

128. KE, 393.

129. $H V, 55$. 
La verdad, entonces, deja de ser un enunciado para trasformarse en el medio histórico y polémico de comunicación ${ }^{130}$. Nadie tiene el saber absoluto ni capta todo el ser. Por eso: «Ce qui importe, c'est alors de retrouver les implications ontologiques des 'actes originaux' para lesquels le moi s'ouvre à l'autre, passe du souci de soi à la disponibilité, de l'avarice au don" " ${ }^{131}$. En este sentido la indisponibilidad es lo que convierte al hombre en mero objeto y «la libertad humana es la dimensión de disponibilidad que el sujeto hombre tiene de sí mismo» 132

En todo caso, la libertad humana es 'situada' desde su limitación y expresada en unas significaciones de praxis con una reflexión crítica y ontológica, en tensión, con una herencia filosófica «vers l'horizon de totalité de l'existence humaine que j'appelle monde ou être» ${ }^{133}$. El progreso de una 'antropología filosófica' se hace siempre al dilucidar esta totalidad.

El camino de la libertad es desde el fondo de la situación hacia el horizonte de totalidad. Este proceso tiene el ritmo de un drama, con una «ontología paradójica», hacia una "ontología reconciliada» ${ }^{134}$. Si el drama ontológico se convierte prematuramente en representación, desemboca en el fariseísmo ${ }^{135} \mathrm{o}$ en ontologización de la ruptura-falta con una liquidación total de la libertad, cuando en realidad «el ser de la libertad no es limitativo, sino en cuanto es constitutivo» de modo que «la cautividad y la liberación de la libertad son un sólo y mismo drama» ${ }^{136}$. Y en definitiva: «L'achèvement de l'ontologie ne peut pas ne pas être une libération» ${ }^{137}$.

La comprensión exacta de la libertad concreta colabora más de lo que parece a disolver el fantoma del Ego trascendental y el espíritu de sistema ${ }^{138}$. La vida y la corporalidad resisten tenazmente contra este 'genio maligno', le obligan a una mayor atención hasta llevarle a una «Poética de la libertad» arriesgada, encarcelada y obscura, desde la espontaneidad corporal. La danza es la imagen de esta libertad ${ }^{139}$.

La ontología es siempre síntesis de sentido y presencia. No se trata sólo de una patética. Hay algo más, y en esto, si se puede hablar así, se supera a Sartre

130. $H V, 59$

131. $H V$, 161. J. Ma ., Ortega Ruiz, «Paul Ricoeur: Hermenéutica y ontología». Anthropologica, 1 (1973) 137-149. Subrayado mío.

132. R. FLóREZ, Libertad y liberación. Valladolid 1975, 61.

133. $H V, 226,163$. Subrayado mío.

134. VI, 21, 22.

135. VI, 25.

136. $V I, 30,32$.

137. $V I, 32$.

138. VI, 35.

139. VI, 456. 
y al primer Heidegger. Se intenta sobrepasar la patética, primera parte de toda antropología filosófica, a la búsqueda de una totalidad, por más peligrosa que ésta sea, y nada se preste tanto a la impostura que quizá nunca se acaba ${ }^{140}$. En este camino la angustia nos advierte de los peligros de la identidad totalitaria apresurada mientras la alegría testifica nuestra participación en la ausencia del ser de los seres ${ }^{141}$, mientras avanzamos como extraños y extranjeros al encuentro del nuevo mundo ontológico ${ }^{142}$ que destruye al paso la alienación, por la fuerza de la libertad.

Ricoeur no intenta una ontología unificada ni siquiera una ontología separada, sino una re-fección metafísica que irá desarrollada mediante el rodeo de la interpretación crítica. En este sentido también el psicoanálisis apunta indirectamente a una ontología para descifrar la condición ontológica del hombre ${ }^{143}$. Es preciso ir, más allá de la representación, a la realidad del sum. Cuando se afronta la totalidad solamente a partir del hombre, como simple sujeto protagonista de la historia y del mundo, se recae en el humanismo y se disimula la implicación ontológica del mismo ${ }^{144}$.

Para Ricoeur, el segundo Heidegger significa el paso de una analítica del ser desde el «Da-sein» a un análisis del ser desde el corazón del lenguaje: La palabra es el $D a$ del $D a$-sein en el segundo Heidegger ${ }^{145}$. La palabra es ahora la llave de la clausura y la apertura del hombre. El poeta es el testigo de la poderosa energía del ser fundante del hombre y su lenguaje. La serenidad universal y cósmica capaz de escuchar, todo de todos, es el talante más propio del poeta pastor de la espontaneidad de la vida y sus voces. Ahora: «La tâche d'une anthropologie philosophique est de montrer dans quelles structures ontiques le langage advient» ${ }^{146}$.

El símbolo va a ser la herramienta de esta nueva ontología no racionalista pero llena de fe en la inteligencia. Ahora bien, una ontología del lenguaje es el horizonte último del camino. En otro caso, el símbolo se convertiría en un ídolo y el apunte ontológico en gnosis racionalista para recaer fatalmente de nuevo en el «saber absoluto en sentido hegeliano» ${ }^{147}$, que maneja arbitraria-

140. $H F, 66$.

141. $H F, 122$.

142. $S M, 75$.

143. $C I, 23-24,68$.

144. CI, 228. Nuestro autor aduce aquí también el planteamiento de M. Heidegger. Cfr. también L. Althusser, La revolución teórica de Marx. Trad. castellana de M. Harnecker, México 1973, en especial el cap. VII.

145. CI, 231.

146. CI, 261.

147. $C I, 327,328$. 
mente sus fundamentos históricos. En esta última línea, una cierta muerte de la metafísica es necesaria en cuanto destrucción del sistema que impide la presencia del ser ya con un puro formalismo textual, ya por un proceso de reificación de la palabra viva.

La nueva ontología es una resituación de la 'totalidad del ser' que anuncia una nueva esperanza ${ }^{148}$. Desde la tradición filosófica se trata de reinterpretar la libertad kantiana en un contexto hegeliano, reducido el idealismo a sus justos límites humanos por una crítica realista de inspiración kantiana no convertible en mera epistemología, más allá por tanto, de Kant y Hegel. Una 'filosofía de los límites' con una 'exigencia práctica de totalización' es, a juicio de Ricoeur, la propuesta filosófica más próxima a la «libertad en esperanza» ${ }^{149}$. Hegel es importante en cuanto anuncia una teleología en dialéctica con la arqueología freudiana.

La palabra del poeta y del pensador actúan como despertadores del olvido del ser, para una ontología en esperanza. Se trata de una lógica de la plenitud y la superabundancia, no etérea-idealista de lo que nadie es dueño, sino de la dialéctica esperanza-desesperanza ${ }^{150}$. Permítasenos citar un texto decisivo a este respecto: «Notre critique de la métaphysique et de sa quête de réconciliation rationnelle doit accéder à une ontologie positive, par-delà le ressentiment et l'accusation. Une telle ontologie positive consiste dans une vision entièrement non éthique, celle que Nietzsche décrit comme 'l'innocence du devenir' (die Unschuld des Werdens). C'est là un autre nom pour 'par de là le bien et le mal». Certes, cette sorte d'ontologie ne peut devenir dogmatique sous peine de retomber sous ses propres critiques; elle doit rester une interprétation, inséparable de l'interprétation de toutes les interprétations; et il n'est pas sûr qu'une telle philosophie puisse échapper a l'auto-destruction» ${ }^{151}$.

Nuestro respeto de la palabra es nuestro respeto al ser. La unión del ser y la palabra viva lleva al hombre a la totalidad de la existencia; y: «Par le moyen du logos, la question de l'être est portée au langage; grâce au logos, l'homme émerge non seulemente comme une volonté de puissance, mais comme un être qui interroge sur l'être» ${ }^{152}$. Es preciso que mueran los ídolos para que los símbolos del ser hablen ${ }^{153}$.

El discurso simbólico-metafísico se presenta como eclosión ontológica de

148. $C I, 397$.

149. $C I$, 403. M. MACEIRAS, «Paul Ricoeur», $P, 126$ (1976) 143.

150. P. RiCOEUR, «Approche philosophique ou concept de liberté religieuse», $A F, 2-3$ (1968) 238: Respuesta a Panikker.

151.' $C I, 447$.

152. $C I, 453$

153. $C I, 457$. 
toda existencia y capacidad dormida: «La expresión viva es la que dice la existencia viva» ${ }^{154}$. Tal es el poder de detección ontológica de la poesía: «Apercevoir, contempler, voir le semblable, tel est, chez le poète bien sur, mais chez le philosophe aussi, le coup de génie de la métaphore que joindra la poètique à l'ontologie»' ${ }^{155}$.

La verdad es ahora tensión entre el lenguaje y su mundo de referencia, disimetría ontológica entre sujeto y predicado, entre semiótica y semántica. El reino filosófico se inicia en el seno y desde el origen de un reino de la metáfora ${ }^{156}$. Por eso: «Le dernier problème critique concerne la portée ontologique du langage métaphorique» ${ }^{157}$. La metáfora al presentar el mundo de un modo nuevo plantea interrogantes ontológicos. Más allá de su talante afectivo la poesía posee valor metafísico. En la opacidad de las palabras la referencia autre no se identifica con referencia nulle ${ }^{158}$.

La metáfora es una trasgresión del código, conducente a una redefinición del mismo y su pertinencia: «Todo discurso poético es una 'redescripción por la ficción', acercándose así Ricoeur a Nelson Goodman y a Max Black» ${ }^{159}$. De la semejanza se pasa a la diferencia. Se trata de una reevaluación total del discurso sin destruirlo. Por ella la metáfora viva supera el dualismo de la «mitología blanca» de Derrida ${ }^{160}$.

Sin destruir el discurso, la imagen poética lo coge a contrapie; los sistemas simbólicos «refont la réalité», acrecientan el ser por la innovación desde lo acostumbrado para avanzar más allá de la «segunda naturaleza por la que olvidamos la primera» en expresión que M. Proust aplicara a la costumbre. «Pour Nelson Goodman, la métaphore est une application insolite, c'est-adire l'application d'une etiquette familière, dont l'usage par conséquent a un passé, à un object nouveau qui, d'abord, résiste, p̉uis cède» ${ }^{161}$. Hay una tensión entre el «est» y el «n'est past». La ficción lleva a una redescripción sobre el lenguaje inmediato. Pero lo que antes era ficción introduce un nuevo mundo ${ }^{162}$, pues no se trata de una mera semejanza carente de implicaciones

154. M.V, 61 .

155. $M V, 40,60$.

156. P. GISEL, «Paul Ricoeur ou le discours entre la parole et le langage». $R P h T, 2$ (1976) 103, 101, 107. $M V, 94$.

157. $M V, 108$.

158. $M V, 139,309$.

159. C. DÍAZ-M. MACEIRAS, Introducción, 235.

160. C. DiAz-M. Maceiras, Ibidem, 236-238. B. HenRy-Levy, La barbarie con rostro humano. Traducción castellana de Monteávila, Barcelona 1978.

161. $M V, 296$.

162. $M V, 310-312$. 
ontológicas. La verdad es ahora tensional y la construcción de la realidad debe ser estereoscópica (B. Stanford): «Això era i no era» 163 .

La noción de ser refleja la riqueza del empleo del verbo «ser». Ya en Aristóteles aparece la «pluralidad de esferas del discurso y la fecundidad de la intersección de sus indicadores semánticos» ${ }^{\cdot 164}$. Tal multiplicidad rompe la unicidad, que hace de la ontología una teleología ingenua, y la convierte en «una dialéctica de la escisión y de la finitud» ${ }^{165}$, como ha apuntado Aubenque.

Ahora el tema de la sustancia se convierte en una encrucijada multidimensional y la ontología se dirige a la restauración de un discurso otro, que antes no parecía discurso propiamente. Ello nos pone en guardia contra la confusión de la filosofía, de la sustancia como una filosofía de la permanencia o de la identificación del cambio con el eterno retorno.

Al llevarnos de la ingenuidad a la admiración permite criticar al ser desde lo mismo y también desde lo otro por una dialéctica del ser y del no-ser, para dar en una ontología inacabada grávida de múltiples desarrollos ${ }^{166}$.

La analogía se presenta ahora como intersección entre diferentes esferas de discurso en vistas a una ontología relacional de comunión y diferenciación del ser, y el movimiento aristotélicố indica la trepidación diferencial de la existencia; el ser como acto deviene la clave de bóveda de la arquitectónica arqueológica que intenta ser, sin conseguirlo definitivamente, la ontología.

Esta nueva analogía metafórica, activadora en la poesía, despierta una visión más amplia, lleva la palabra a su origen y hace presente el mundo. Así, la trasgresión metafórica es la ruptura de la metafísica muerta y entonces el lenguaje filosófico anticipa lo no dicho pero indicado por la metáfora. La ontología así anunciada rompe con la metafísica dualista, sensible o no-sensible, como lo hace la poesía auténtica: "La poésie, bien plutôt, remonte la pente que descend le langage quand la métaphore morte va se coucher dans l'herbier» 167 .

La entropía de lenguaje es lo que precisamente quiere remontar, frente a Derrida, una filosofía de la metáfora viva, sin dejar de reconocer, con el mismo Derrida, que: «La fleur qui éclôt finit un jour dans l'herbier, comme l'usage dans l'usure» ${ }^{168}$. Por eso no se puede pensar en una neutralidad metafísica

163. $M V, 321$.

164. $M V, 336$.

165. $M V, 337$.

166. P. Ricoeur, Platon et Aristote. Etre, essence et substance chez Platon et Aristote.

CDU. 'Les cours de la Sorbonne', Paris 1968, 64, 55,54.

167. $M V, 361$.

168. $M V, 362$. 
porque sería manejar simultáneamente una ontología inconfesada de la metáfora muerta.

La metáfora muerta puede disimularse en el concepto y construir una ontología sistemática. La metáfora viva desenmascara el concepto. Esta ontología enmascarada es el conjunto de todos los filosofemas para Derrida y surge allí donde se produce la usura de la metáfora. Entonces, como en Nietzsche, las verdades son ilusiones que olvidan que lo son, metáforas que han perdido su origen sensible ${ }^{169}$.

La metáfora viva, por el contrario, anuncia una ontología militante que en cuanto olvida su dinamismo permanente se petrifica; su detención es su muerte. Por eso precisa mantener una dialéctica constante entre universalización y concretización, porque si el símbolo se convierte en estatua de sal deviene ídolo automáticamente. El concepto vivo se mueve por la vehemencia ontológica de un campo en parte desconocido, pero a la vez presentido en la metáfora viva ${ }^{170}$.

El discurso vivo está transido de atracciones y repulsiones, de interacciones y descentraciones, sin descanso en un saber absoluto destructor de las tensiones, aun cuando se mueva en una frontera de constitución de la comprensión histórica como fusión de horizontes ${ }^{171}$. La interpretación clarifica y activa el dinamismo metafórico que el concepto representativo detiene y fija ${ }^{172}$. Por ella el lenguaje filosófico se mantiene abierto al ser y en el ser: «ll faut donc ébranler le régne de l'objet, pour laisser être et laisser se dire notre appartenance primordiale à un monde que nous habitons, c'est-à-dire qui, tout à la fois, nous précede et recoit l'empreinte de nos ouvres» ${ }^{173}$.

En el discurso poético se trata precisamente de una dinámica tensa entre el ser y el no-ser, no de un irracionalismo: «seule une théorie 'tensionnelle' de la vérité métaphorique permet de préserver l'équilibre et d'échapper à l'alternative: naiveté ontologique ou démythisation critique» ${ }^{174}$. El poeta descubre la realidad en eclosión ${ }^{175}$, articula y preserva, con otros modos de discurso, la experiencia de pertenencia que incluye al hombre en el discurso y el discurso en el ser, como el discurso filosófico expone el poder de distanciación: «Ce qui est ainsi donné à penser par la verité 'tensionelle' de la poésie, c'est la dialecti-

169. J. DERRIDA, Mythologie blanche, 15. Citado por $M V, 364$.

170. $M V, 379$.

171. $M V, 382$.

172. $M V, 387$.

173. $M V, 387$.

174. J. GREISCH, «Bulletin de philosophie. La tradition herméneutique aujourd'hui: H. G. Gadamer, P. Ricoeur, G. Steiner». RPhT, 61 (1977) 295.

175. $M V, 392$. 
que la plus originaire et la plus dissimulée: celle qui règne entre l'expérience d'appartenance dans son ensemble et le pouvoir de distantiation qui ouvre l'espace de la pensée spéculative» ${ }^{176}$.

Así rompe el eterno presente ${ }^{177}$. La filosofía de la voluntad debe ser una filosofía de la libertad, no un espectáculo voluntarista. Discernir la nueva creación humana libre es la nueva ontología que estalla y se muestra en el discurso como apertura y delimitación del ser por una ontología de la finitud frente a Husserl idealista ${ }^{178}$.

\subsection{El hombre y su discurso}

Podemos decir con Paul Ricoeur: «Il me paraît qu'il est un domaine sur lequel se recoupent aujourd'hui toutes les recherches philosophiques, celui du langage»» ${ }^{179}$. Se trata de una filosofía que da cuenta de las múltiples funciones del significar humano y sus implicaciones, pues por el lenguaje se comprende el hombre, y «la asfixia de la palabra es la enfermıedad de una civilización», nos dice Hesnard junto con A. Beguin: «No hay nada más pernicioso que lo que violenta el lenguaje, pues la necesidad más honda del hombre no es la justicia ni el orden, sino la significación» ${ }^{180}$.

En cierto sentido puede decirse que el hombre lo es porque significa, y el lenguaje es como una institución en la que vivimos y morimos. Por nuestro discurso nos constituimos unos a otros al aprobarnos y rechazarnos. Por eso no podemos reducir al otro a una parte de nuestro discurso pues cada uno posee la totalidad de la experiencia humana desde una cierta perspectiva ${ }^{181}$. Como diría Nietzsche: «En todo caso, hablar del espíritu y del bien, como lo hizo Platón, significaría poner la verdad cabeza abajo y negar el perspectivismo, el cual es condición fundamental de toda vida» ${ }^{182}$.

Desde pensadores aún más próximos a nosotros debemos aludir al discurso uniformante (idiotizante) criticado desde diversos puntos de vista por Mar-

176. $M V, 399$.

177. ...«frente a la fe en que lo que es es lo que es, y por tanto tiene que ser lo que es, hay una falta de fe que piensa que lo que es es lo que es, sin más, y que puede que no esté tan mal correr el riesgo de mirar a ver si el hecho de que lo que es sea lo que es es tan necesario como ello mismo lo asegura»: A. GARCía CALvo, y otros: «Un manifiesto de la Comuna antinacionalista zamorana», El País. Arte y pensamiento. Año I, n. ${ }^{\circ} 6,20-11-76$, II.

178. P. RICOEUR, «Phénoménologie et herméneutique». PhF, 1 (1975) 38.

179. DI, 13 .

180. Citado por A. HeSnARd, De Freud a Lacan. Trad. castellana de eds. Mtz. Roca. Barcelona 1976,121 . Subrayado mío.

181. $H V, 70$.

182. F. NiETZSCHE, Jenseits von Gut und Böse. Trad. castellana de A. Sánchez Pascual. Madrid 1972, 18. 
cuse, M. Foucault y A. García Calvo ${ }^{183}$. Ricoeur afirmará a su vez: «La vérité, comme dit Jaspers, n'est pas autre chose que le 'philosopher en commun'» ${ }^{184}$. Por ello, aun cuando el discurso filosófico se distancia de la realidad al teorizarla no tiene que falsificarla necesariamente. Para Ricoeur, la relación de manifestación-disimulación entre discurso filosófico y realidad histórica «es la forma extrema del estatuto del lenguaje en el mundo» ${ }^{185}$.

Una verdadera teoría del hombre no puede por menos de defender, frente a las posiciones de la unificación, la vanidad o la envidia que no las reconocen: «...les relations d'homme à l'homme: sphère économique de l'avoir, sphère politique du pouvoir, sphère culturelle de la reconnaissance mutuelle» ${ }^{186}$, y buscar un reconocimiento concreto y total que no pasa frívolamente sobre los otros. Por lo cual es preciso tomar conciencia de que el discurso nace de la vida y no del sujeto puro ${ }^{187}$. Todo discurso significativo vive desde ese fondo no codificado aún de la vida, $y$, por tanto, la libertad humana está unida a la materia indefinida y al hecho puro del existir viviente ${ }^{188}$.

Es a través del mundo como el hombre crea la mediación entre su ser y la totalidad. El lenguaje es el alumbramiento de esta situación en su medio cultural: «Le langage lui-même, en tant que milieu signifiant, demande à être référé à l'existence» ${ }^{189}$. Es en el lenguaje donde se presenta toda comprensión óntica y ontológica de la realidad. Como dice E. Lledó: «Es, pues, nuestro lenguaje el que nos da la forma de experiencia que imaginamos tener del mundo» ${ }^{190} . \mathrm{El}$ hombre se comprende a través del lenguaje.

Ahora bien, para Ricoeur, la polisemia y el simbolismo pertenecen a la constitución y el funcionamiento del lenguaje. El análisis estructural es necesario y fundamental para el conocimiento del lenguaje, por eso es preciso pasar del lenguaje de la «lengua» al discurso real. Éste es un acto de comunicación de alguien a alguien ${ }^{191}$, como aseguran Humbolt y Chomsky.

No se trata de quedarse con el planteamiento fenomenológico frente a la semiología actual, sino de descubrir cómo ésta sólo es posible a partir de la

183. H. Marcuse, One dimensional Man. Trad. catalana de M. Carbonell. Barcelona 1968.

184. $H V, 71$.

185. $H V, 76$.

186. $H V, 116$

187. $H V, 276$.

188. $H V, 389$.

189. $C I, 20$.

190. E. LLEDo, Filosofía y lenguaje. Barcelona 1970, 61.

191. $C I, 89,90$. Por otra parte «No se trata de oponer diacronía a sincronía como han hecho algunos críticos del estructuralismo; Ricoeur aquí da la razón a Lévi-Strauss y piensa que esto es un malentendido. Se trata de que el sistema es el verdadero lugar en que los signos son significantes»: A. PinTor Ramos, «Paul Ricoeur», P, 122 (1975) 101, 108. 
comprensión de la función simbólica en cuanto «la naissance même de l'homme à l'ordre des signes» ${ }^{192}$ a partir de un mundo opaco en el grado cero de su expresión. Ricoeur citará a Lévi-Strauss, discípulo de M. Mauss, para afirmar que la función simbólica es el origen, no el resultado de la vida social ${ }^{193}$. Los ídolos petrificados, las fabulaciones e ilusiones reificantes son la muerte del lenguaje simbólico y en definitiva la muerte del hombre y su mundo ${ }^{194}$. Aquí el hombre pierde su capacidad de escuchar y descubrir.

Ricoeur enfrenta su teoría de la metáfora viva a una retórica de meras sustituciones, tipificada por Fontanier ${ }^{195}$. La sustitución pertenece a la relación paradigmática del orden semiótico regida por la ley de binariedad de Jacobson y los estructuralistas, mientras la metáfora viva se desarrolla en el campo sintagmático en el cual se cumple el sentido de la frase. Las palabras, según I. A. Richards, frente a Fontanier, solamente tienen sentido en cuanto son miembros - desmembrados-de una frase ${ }^{196 .}$

Las distintas significaciones de una palabra expresan las luchas y convergencias de los campos semánticos. Los desplazamientos de significación aseguran la comunicación según el principio omnipresente de la libre acción. Así, para I. A. Richards nuestro mundo es un mundo proyectado y lleno de trazos sacados de nuestra vida e impreso sobre metáforas espontáneas anteriores ${ }^{197}$ : «Il faut donc avouer que la métaphore relève autant de la 'pragmatique' que la 'sémantique'» 198 .

Para Ricoeur se trata de abordar el enigma de la emergencia de una "nueva significación más allá de toda regla ya establecida'; el poeta descubre un conjunto de relaciones originantes de nueva significación, un nuevo mundo, por eso la metáfora es como un 'poema en miniatura' 199 . Y sólo la metáfora auténtica, la metáfora viva, es al mismo tiempo acontecimiento y sentido ${ }^{200}$.

A partir de la acumulación de sentidos en la polisemia y la ‘vagueness', la innovación metafórica muestra que: «Tout changement implique le débat entier de l'homme parlant et du monde» ${ }^{201}$. Según una idea de S. Ullmann, el lenguaje no es ni 'sistemático' ni completamente 'no sistemático'; está afectado incluso por lo no estrictamente lingüístico, como lo social, lo científico, lo

192. CI, 254.

193. CI, 254.

194. $C I, 328$.

195. $M V, 64-81$.

196. $M V, 99,102$.

197. $M V, 108$.

198. $M V, 116$.

199. $M V, 116,120-121,279$.

200. $M V, 127$.

201. $M V$, 161. Subrayado mío. Y $C I$ : «La parole nous atteint au niveau des structures 
cultural en general. Jacobson nos invitaría a ir más lejos para «renunciar a llamar código a un sistema tan poco sistemático» ${ }^{202}$.

Mientras el discurso ordinario elimina todos los significados menos uno, la metáfora nos dice Ricoeur, condensa todos los significados y añade uno más. El contexto 'configura' (Firth)o 'co-apta' (Benveniste) la posición del significado, con la particularidad de que en el contexto no se trata únicamente de lo escrito sino también de la acción, el trabajo, etc..., que lleva a un sentido y una denotación ${ }^{203}$.

$\mathrm{El}$ discurso poético intercepta una referencia demasiado inmediata para dejar ver otro sentido y las realidades aludidas pero en nuevas dimensiones. Según Ricoeur, la suspensión de la referencia inmediata solamente es la condición para otra referencia más profunda ${ }^{204}$, y en línea con Susan Langer, se pronuncia por la superación del dualismo o alternativa entre realidades verificables e inverificables ${ }^{205}$. Ricoeur confirma así: «Dire, avec Susan Langer, que lire un poème c'est saisir 'un fragment de vie virtuelle' (a piece of virtual life), c'est rester dans l'opposition vérifiable-invérifiable» ${ }^{206}$.

Según Jacobson, la poesía es una re-evaluación total del discurso ${ }^{207} \mathrm{Tal}$ es la obra de la metáfora. Es preciso superar el dualismo entre denotación y connotación pues los símbolos, según Nelson Goodman, hacen y rehacen el mundo ${ }^{208}$; la palabra y el mundo se construyen mutuamente. A partir de Nelson Goodman, Ricoeur cree poder establecer las afirmaciones siguientes:

1. El sistema simbólico es referencial como el discurso descriptivo.

2. Los sensa que se adhieren al sens no son menos reales que las referencias del discurso científico.

3. La connotación es referencial como la denotación, aún cuando la metáfora es una aplicación insólita del discurso.

4. Tanto los modelos científicos como los modelos poéticos son instrumentos de redescripción conforme a las teorías de Max Black y Mary Hesse ${ }^{209}$.

5. La referencia no-ostensiva también es un modo de relación hombre-

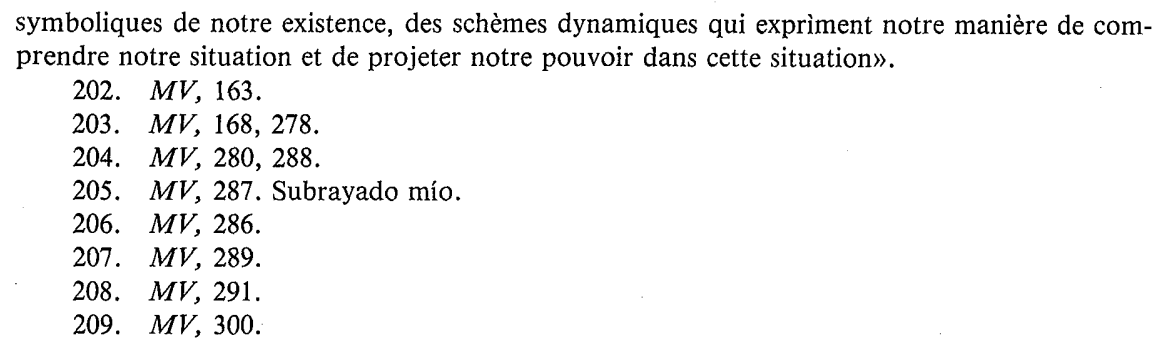


mundo ${ }^{210}$. El mundo es el conjunto de referencias abiertas por los textos, y comprender un texto es hacer «éclater» nuestra situación ${ }^{211}$.

Entonces, cómo distinguir entre el discurso humano verdadero y la ideología? En principio conforme a la teoría de la pluralidad de discursos, es preciso no considerar la ideología de un modo tan negativo como acostumbra a hacerse. Buscar un pensamiento libre frente a toda operación de intimidación de unos contra otros, pasar por Marx sin hostigarlo, y resituar el problema de la «dominación» en el fenómeno de la «integración social» ${ }^{212}$.

La ideología no es solamente el pensamiento de mi enemigo que el desconoce y yo sé. Hay que indagar una teoría de la acción capaz de arrancarse a la condición ideológica del conocimiento práxico ${ }^{213}$. La ideología responde a la necesidad que tiene todo grupo social de darse una imagen y responde más a un deseo de justificación que de movilización, aunque al justificar al grupo en su 'razón' de ser lo que es, también lo anima ${ }^{214}$.

El pensamiento se trasforma de mera creencia dóxica en activador dotado de una retórica ritualizada, ortodoxa, con un exceso de legitimación y aparato formal, en función de una eficacia social y un poder nunca criticado ${ }^{215}$. Entonces la consciencia queda sujeta a la eficacia histórica, sin capacidad de autocrítica ${ }^{216}$ : «C'est ainsi que, pour ma part, j'assume la thèse de Habermas que tout savoir reste porté par un intérêt et que la théorie critique des idéologies est elle-même portée par un intérêt, l'intérêt pour l'émancipation, c'est-adire pour la communication sans borne et sans entrave» ${ }^{217}$.

Por tanto, es preciso un trabajo paciente de recuperación de nuestra totalidad histórica para no convertir a su vez la teoría crítica en un saber absoluto y por tanto ideológico. El pensamiento debe ser un proceso abierto que ninguna visión debe cerrar ${ }^{218}$, pues se hurtaría a los demás lenguajes y no tendría en cuenta todos los presupuestos a clarificar, ni la polisemia del símbolo, ni la comprensión del otro ${ }^{219}$, ni el discurso roto o prohibido ${ }^{220}$.

Quede bien claro que no existe el espectador imparcial ideal: «It is a great

210. P. Ricoeur, «Evénement»: M. Philibert, Paul Ricoeur, 181, 182.

211. P. RICOEUR, «Evénement», $A F, 2$ (1971) 20.

212. P. RICOEUR, «Science», RPhL, 72 (1974) 328-329.

213. P. RiCOEUR, Ibidem, 330.

214. P. RiCOEUR, Ibidem, 331, 332.

215. P. RICOEUR, Ibidem, 344.

216. P. RICOEUR, Ibidem, 253.

217. P. RICOEUR, Ibidem, 354.

218. P. RicOEUR, «Phénomenologie», PhF, 1 (1975) 43.

219. S. HACKETT, «Philosophical», International philosophical Quaterly, 9 (1969) 36.

220. P. BourgeoIs, «Hermeneutics», $P h T, 4 / 4$ (1971) 238. SM, 316 . El deseo del hombre tirano es el que engendra los falsos lenguajes. 
illusion, Ricoeur says, to think that one could make himself a pure spectator, without weight, without menfory, without perspective, and regard every thing with equal sympathy» 221 .

El hombre se autorevela por diversos caminos y se sitúa en la realidad total por medio de sus lenguajes. El símbolo poético manifiesta este proceso en su mismo origen ${ }^{222}$. Y es precisamente la poesía la que permite al hombre habitar sobre la tierra, según la expresión de Hölderlin ${ }^{223}$. La interpretación filosófica debe elevar estos símbolos a categorías estructurales y existenciales. Esto tiene para el pensamiento de Ricoeur una categoría fundamental respecto al mundo y a la trascendencia: «La libertad» 224 . En el reino de la palabra se encuentra Ricoeur con el estructuralismo, pero para Ricoeur la multivocidad es una riqueza del lenguaje no una enfermedad a corregir ${ }^{225}$. La misma clausura del discurso a nivel semiótico invita a una apertura a nivel de frase. El éxito del estructuralismo no está en inducir una estructura desde los datos, sino en la construcción de un modelo, por parte del investigador, capaz de hacerlos inteligibles ${ }^{226}$. Para Ricoeur el análisis estructural es solamente un primer paso, que debe alcanzar mayor plenitud; tal análisis 'no sobra pero no basta', como decía Deaño de la filosofía Analítica.

\subsection{Lo simbólico es regresivo y prospectivo}

El discurso simbólico pone el lenguaje en «estado de emergencia», según una expresión de Bachelard ${ }^{227}$ e introduce un nuevo mundo con su especial prospectiva y su nueva libertad testigo del hombre nuevo. Se trata de la libertad polivalente apuntada por la dimensión poética existenciál que, por otra parte, se hace concreta sin petrificarse ${ }^{228}$ en una objetividad no reificada, reveladora de la libertad según una cadena de figuras, señaladas por la fenomenología del espíritu, con perspectiva de liberación ${ }^{229}$.

Se pone en cuestión la objetividad pasada y se contempla un nuevo hori-

221. Texto de $S M$ citado por J. D. StewarT, «Paul Ricoeur», PhT, 4/4 (1968) 227. El mismo Ricoeur se reconoce en la tradición que pasa por Jerusalén y Atenas, y afirma que el filósofo sin pasado es un impostor.

222. M. SANTOS, «La 'Repetición’». Stromata, 27 (1971) 503.

223. M. SANTOS, Ibidem, 510, CI, 456.

224. C. DíAz-M. MACEIRAS, Introdución, 241.

225. A. Pintor Ramos, «Paul Ricoeur», P, 122 (1975) 104-105.

226. A. Pintor Ramos, Ibidem, 110.

227. Citado por Ricoeur y resaltado especialmente por P. JAVET, «Imagination», $R P h T, 3$ (1967) 149.

228. $K E, 213,214$.

229. KE, 291, 294. 
zonte en la reconstrucción del hombre concreto e inefable ${ }^{230}$. De este modo el ser humano «ejerce la profecía de su propia existencia» ${ }^{231}$. Se trata de una fuerza militante al servicio de la anticipación del futuro a partir de la contemplación respetuosa del presente ${ }^{232}$.

El símbolo inmerso en la realidad y anunciador de lo distinto «da qué pensar», suscita la admiración y nos presenta un mundo concreto de reflexión, al estar unido a lo cósmico y alejarnos simultáneamente de él en un esfuerzo de vincularnos a la totalidad. Desde su implantación concreta, arqueológica, se muestra a la vez como camino de descubrimiento y prospectiva de nosotros mismos para convertirse en nuestro guía ${ }^{233}$. En esto coinciden la imagen poética, el psicoanálisis onírico y las hierofanías cósmicas que nos sitúan en el origen del discurso humano según dirá Bachelard ${ }^{234}$.

Todo ello dentro de un estricto programa de austeridad filosófica, según Ricoeur: «Ce n'est donc pas la regret des Atlantides effondrées qui nous anime, mais l'espoir d'une récréation du langage; par-delà le désert de la critique, nous voulons à nouveau être interpellés» ${ }^{235}$. A la vez se trata de una apuesta por el hombre: «je parie que je comprendrai mieux l'homme et le lien entre l'être de l'homme et l'être de tous les étants si je suis l'indication de la pensé symbolique» ${ }^{236}$.

Ricoeur va a intentar verificar esta apuesta por una analítica de la libertad: de la libertad alienada en la ruptura del hombre a la libertad liberada de su reconstrucción ${ }^{237}$.

Con la simbólica se rompe el círculo encantado de la «conscience de soi», al quebrar la situación privilegiada de la reflexión y quedar entre paréntesis la evidencia del cogito ${ }^{238}$. El símbolo parte de lo concreto y lo rebasa. Supera la significación unidimensional de modo que incluso el concepto del «ser» conforme a la interpretación de Aubenque no es sino: «...l'unité problématique d'une pluralité irreductible de significations» ${ }^{239}$. En tal contexto escribe Ricoeur: «Je dirai qu'il y a symbole là où l'expression linguistique se prête par son double sens ou ses sens multiples à un travail d'interprétation» ${ }^{240}$.

\footnotetext{
230. $K E, 357-359$.

231. $H V, 130$.

232. VI, 448.

233. $S M, 20, S M, 324$.

234. Citado por $S M, 20$.

235. $S M, 325$.

236. SM, 330.

237. $S M, 330$.

238. SM, 331.

239. Citado por $D I, 32$.

240. DI, 26.
} 
Nuestro autor se propone un plan más austero y realista que el neokantiano Cassirer y menos estrecho que el Aristotélico: «Aristote n'a pas lui-même exploité l'idée d'une transgression catégoriale que quelques modernes rapprocheront du concept de category-mistake chez Gilbert-Ryle» ${ }^{241}$. Se trata de esclarecer la tensión entre lo universal y lo concreto. La polisemia de lo concreto supone un «denominador común» ${ }^{242}$. Por eso, el símbolo no puede evaporarse en la intemperancia alegorizante e ingenua, ni reducirse a un nuevo signo de efectuación descriptiva; parte de lo concreto para rebasarlo pero sin perderlo.

Tal acontece en la obra de arte marcada con unas dimensiones concretas pero con muchos significados que funcionan no solamente como síntoma de regresiones, sino principalmente como sintaxis prospectiva del individuo y la humanidad ${ }^{243}$. Lo mismo puede decirse de las expresiones culturales del ser humano cuyo encadenamiento 'prospectivo', con sus propias regresiones, no es difícil de intuir ${ }^{244}$.

Así, cada corriente cultural se desvía de la anterior desde una perspectiva diferente. Cada obra artística supone otro mundo. Toda metáfora contiene una información «redescriptiva» de la realidad: «Nous sommes arrivés (dice Ricoeur) au voisinage de notre hypothèse le plus extrême: a savoir que la 'métaphorique' qui transgresse l'ordre catégoriel est aussi celle qui l'engendre» ${ }^{245}$.

Se llega así a una «reevaluación total» del discurso por un proceso en el que aquél, primero «se resiste y después cede» según apreciaciones respectivas de Jacobson y Nelson Goodman ${ }^{246}$. Para estas aseveraciones Ricoeur recurre además frecuentemente a Benveniste, Chomsky, Wittgenstein, Austin y Searle entre otros. El discurso simbólico responde precisamente a la experiencia humana de renovación permanente, originaria $\mathrm{y}$, frecuentemente, total ${ }^{247}$. Por eso una filosofía 'fundada y enriquecida' por el símbolo lleva a una modificación cualitativa del hombre y su consciencia reflexiva ${ }^{248}$. Como lo subraya $P$. Javet: "La culture, et ses synonymes 'éducation et Bildung', font fonction de seconde nature, parce qu'elles remodèlent la nature première; en elles se réalise le mouvemente magnifiquement décrit par Ravaisson à l'occasion de l'escrupule limité de l'habitude; c'est en même temps le retour de la liberté à la na-

241. $M V, 31$.

242. $C I, 61$.

243. $C I, 205$.

244. $C I, 241$

245. $M V, 34$.

246. Citado por $M V, 289,296$.

247. M. SANTOS, «La 'Repetición'», Stromata, 27 (1971) 501.

248. M. SANTOS, Ibidem, 510. 
ture par la reprise du désir dans l'oeuvre de culture. Par surdétermination du symbole, cette oeuvre est fortement suturée au monde de la vie (...); en mobilisant toutes nos enfances, tous nos archaïsmes, en s'incarnant dans l'onirique le poétique garde l'existence culturelle de l'homme de n'être qu'une immense artifice, un futile 'artefact', un Leviathan sans nature et contre nature» ${ }^{249}$. Por tanto, no se trata de ninguna alucinación teórica, sino de una dialéctica arqueología-prospectiva siempre unida al más estricto realismo de la vida y el mundo.

\subsection{Filosofía y Hermenéutica}

Por la hermenéutica, el hombre debe recuperar lo olvidado, los lenguajes perdidos, reexaminar los signos y símbolos archivados en contextos rutinarizados pero susceptibles de sugerencias inesperadas más allá de la consciencia inmediata acostumbrada y enclaustrada en sus moldes diarios. Para ello invocará Ricoeur a lingüístas creativos que patrocinan el símbolo desde la lingüística como Benveniste, Jacobson y Chomsky, y especialistas del lenguaje ordinario como Austin y Searle, después de reconocer con una idea común a Waelhens la mayéutica fenomenológica de Husserl antitética de la omnisciencia hegeliana ${ }^{250}$.

Así se avanza hacia una síntesis filosófica actual y siempre provisional para progresar en la experiencia del pálpito de la existencia humana, su 'cs.fuerzo por existir', y su 'deseo de ser' descubierto en sus signos manifestalivos. Se trata de una tensión dialéctica constante entre vida y comprensión, lo concreto y lo universal, la ambigüedad y la clarificación, la práctica y la teoría; la contingencia de las tareas humanas con sus símbolos y la comprensión total del hombre ${ }^{251}$.

El proceso hermenéutico es comunicación permanente y progresivamente aproximativa, lo que le aleja tanto del escepticismo como del eclecticismo pagado de sí mismo, para entrar por los caminos de la simbólica vigilada en sus excesos por las armas de la racionalidad filosófica ${ }^{252}$. También ésta debe denunciarse en sus particulares condicionamientos como la pretendida neutralidad y la claridad lejana de la vida con pérdidas incluso de información y comprensión. Solamente: «With post-critical and intructed naiveté, then, reflection returns to the fullness of living speech with its symbols, but illuminated

249. P. JAVET, «Imagination». RPhT, 3 (1971) 153.

250. E. ReNZI, «Freud», Aut. Aut, 98 (1967) 41.

251. S. HACKETT, «Philosophical», International Philosophical Quaterly, 9 (1969) 17.

252. S. HACKETT, Ibidem, 20. 
now by the dynamic tension which characterizes both the symbols and conflicting interpretations of them» ${ }^{253}$.

De este modo, el hombre se va reconstruyendo desde sus fundamentos, incorporándose «la libertad teórica y práctica que puede razonablemente atribuirse a la existencia humana» .254 desde un discurso que reproduce y da un sentido, procede de un orden y un mundo al que se refiere y cambia e indica un locutor y una realidad. Este discurso parte de la realidad natural, y, a través del reino de la metáfora, se hace filosófico. Toda afirmación filosófica supone un ser, un no-ser, y un ser-como, pero la metáfora no es una simple anarquía del lenguaje, ni la filosofía mera congelación de la metáfora ${ }^{255}$.

El dinamismo de la proposición filosófica supone un distanciamiento de la situación 'natural' que anuncia otro mundo distinto con un discurso pluralista por un «descentramiento de la consciencia hacia nuevos significados que el discurso primero sólo preconiza» ${ }^{256}$.

La hermenéutica busca ahora, en el mutuo respeto, «la fusión de horizontes», según la expresión de Gadamer. A partir del estructuralismo, que es un análisis sintáctico, Ricoeur intenta una hermenéutica que es además análisis semántico ${ }^{257}$. Ambos se funden en el mito para extraer la esencia histórica del hombre. No se trata de conseguir una 'gnosis' divina, sino de sumergirse en la totalidad para una reminiscencia y una prospectiva.

En el surgir de los símbolos se elabora una comprensión según una dinámica restauradora de cuanto da que pensar el símbolo; primero, porque todo símbolo es iconoclasta respecto de otros símbolos por su ponerse a sí mismo en una hermenéutica espontánea, y después porque ésta nos invita a investigar las condiciones de posibilidad del símbolo verificado por su capacidad de esclarecer la realidad humana con una tarea de transformación cualitativa de la consciencia reflexiva por la ruptura de su encantamiento enclaustrado ${ }^{258}$.

Se ofrece, ahora, una oportunidad nueva a la filosofía actual para una lectura distinta de las totalidades y una práctica de control riguroso a la consciencia como origen de sentido.

La hermenéutica se presenta hoy día como la encarnación misma de la filosofía actual: «L'ermeneutica si pone oggi non soltanto como uno dei princi-

253. S. HACKETT, Ibidem, 26.

254. S. HACKETT, Ibidem, 39: «...theorical and practical freedom which can reasonably be predicated of human existence».

255. P. GISEL, «Paul Ricoeur», RPhT, 2 (1976), 103-105.

256. M. MACEIRAS, «Paul Ricoeur», P, 126 (1976) 142.

257. M. MACEIRAS, Ibidem, 149-150.

258. M. SANTOS, «La 'Repetición'», Stromata, 27 (1971) 508, 500. 
pali interlocutori della filosofia, ma come una sua rinouvata incarnazione, adeguata alle richieste speculativi dei tempi moderni» ${ }^{259}$. Una descentración y un extrañamiento de la consciencia en la realidad se hace presente. La filosofía deja de ser la ciencia de las ideas para serlo de la realidad. "Considerata globalmente e nel suo insieme, l'ermeneutica consegue un preciso risultato metodologico: essa prepara la via per una genealogia dell'a priori. Là dove il metodo riflessivo tradizionale discerne una struttura primitiva, irreducibile, il metodo genealogico discerne un'istanza derivata, acquisita» ${ }^{260}$.

Ahora, el significado no es unívoco, y obliga a pensar sus condiciones porque los signos y las figuras expresan la existencia y el esfuerzo humano bajo sus máscaras; y la hermenéutica se presenta como una «técnica de análisis de los textos simbólicos»: «Por lo menos hay dos grandes grupos de hermenéuticas; el primero, cuyos grandes maestros son Marx, Nietzsche y Freud, busca una destrucción de los ídolos creados por los símbolos; el segundo, en cambio, persigue una restauración y reapropiación del sentido a través de los textos cifrados en que se trasmite. Arbitrar este campo escindido e integrarlo en el problema filosófico, esta es una de las razones por las que la hermenéutica interesa a la filosofía» ${ }^{261}$.

En el futuro toda filosofía deberá ser previamente hermenéutica, conocer el psicoanálisis y la semiología para llegar al verdadero ser de las cosas. Por eso, la hermenéutica es desvelamiento, lo contrario de clausura y sistema ${ }^{262}$.

La creatividad de la hermenéutica se muestra en que: «La interpretación de un texto es por consiguiente similar a la interpretación de una pieza musical por el maestro de orquesta. Cada ejecución supone un renovado acontecimiento, pero la partitura es autónoma en su significado» ${ }^{263}$.

Así, la reflexión arrancada a sí misma, se recoge desde los actos y las obras concretas como antítesis mayéutica de la omnisciencia hegeliana de modo que el discurso, aún con tener autonomía, nace en el mundo y responde al mundo, por eso la metáfora de la Naturaleza es figura filosófica del mundo frente a lo muerto y congelado en el sinsentido. La filosofía toma pie en la dinámica del lenguaje como acercarse y distanciarse dialéctiło del mundo interesado en un mayor sentido a partir de los códigos o posibles horizontes de interpretación guiados por el respeto creativo a la realidad, como oportunidad

259. L. OBERTELLo, «Filosofia e interpretazione». Filosofía, 22 (1971) 107.

260. M. CRISTALDI, «La testimonianza», $A F, 3$ (1972) 72.

261. A. Pintor Ramos, «Paul Ricoeur», $P, 122$ (1975) 117.

262. A. Pintor Ramos, «Símbolo, hermenéutica y reflexión en Paul Ricoeur». La Ciudad de Dios, 185 (1972) 487.

263. C. DÍAZ-M. MACEIRAS, Introducción, 195. 
de pensamiento y del símbolo en cuanto lugar central de la múltiples paradoja humana.

La hermenéutica aparece primero como una técnica de análisis de los textos simbólicos, pero a la vez como comprensión de sí mismo, del mundo y del ser, una verdadera empresa filosófica a la búsqueda de las estructuras ónticas de todo lenguaje y de toda arqueología donde se expresa el deseo de ser y el esfuerzo por existir que nos constituye ${ }^{264}$. La filosofía hermenéutica tiende, sin llegar nunca absolutamente a él, hacia un Ursprung que supone un Logos y un Bíos, y se investiga a través del avoir, el pouvoir y el valoir humanos ${ }^{265}$.

La dualidad tensa del hombre, es la dualidad del símbolo que está implantado en el cosmos y el poeta muestra el surgir de la palabra. No se trata de la relación del sentido o la palabra a la cosa, sino de una arquitectura del sentido: «An architecture of sense, in a relation of sense to sense, of a second sense to a first sense. It is that texture which renders possible the interpretation, although only the mouvement effective of interpretation renders it manifest (D. I. 26)» ${ }^{266}$.

Por la hermenéutica se dan pasos de la semántica a la reflexión y de ésta a la existencia y la ontología ${ }^{267}$. Es un camino hacia el punto de partida «in the full language and the arqueology of the subject» ${ }^{268}$. De modo que la hermenéutica no crea nada por sí misma: «For Ricoeur philosophy does not begin anything from nothing. Rather, language precedes it, an in a way, says, everything before philosophy begins. The symbol however, is the gift of language to thought and brings the duty to think, to begin philosophical discours from what already goes before it. Thus the symbol demands reflection. The symbol frames an appeal not only to interpretation, but also to philosophical reflection (D. I. 46)» ${ }^{269}$.

Se trata de llegar a tematizar la universalidad, la temporalidad y la exploración ontológica. El símbolismo por el sentido y la vida orienta la reflexión. Esta toma la totalidad con el comienzo y el fin. Las creaciones particulares se entraman en la universalidad: «Thus for Ricoeur, to justify the recourse to symbolism in philosophy is finally to justify the cultural contingency, equivocal language, and the war of hermeneutics in the very bosom of reflection (DI.50)» ${ }^{270}$.

264. A. Pintor Ramos, $P, 122$ (1975) $118,120,123$.

265. P. Bourgeols, «Hermeneutics», $P h T, 4 / 4$ (1971) 238.

266. P. Bourgeors, Ibidem, 234-237.

267. P. BourgeoIs, Ibidem, 239.

268. P. BOURGEOIS, Ibidem, 240.

269. P. BourgeoIs, Ibidem, 240.

270. P. BourGeOIS, Ibidem, 241. 
Para Ricoeur los símbolos son como «detectores de la realidad» ${ }^{271}$, ello implica una no reducción a un sistema seguro como el vacío lenguaje de un cálculo matemático ${ }^{272}$. Esta dialéctica símbolo-reflexión debe mantenerse por su relación a la existencia, a un mundo manifestado por los símbolos. Ésta es la obra y el hombre cumplido por Ricoeur en el análisis de la voluntad ${ }^{273}$. Es la incidencia de la reflexión en el simbolismo, en un contexto de libertad que afecta al símbolo mismo, que en el largo camino del descubrimiento del ser capta la creatividad-libertad en su mismo ser con una nueva manera de cuestionar. Es la diferencia entre la dura crítica del existencialismo y el sentido prospectivo del personalismo para promover la acción y dilucidar la significación ${ }^{274}$.

En la encrucijada de las urgencias inaplazables y las aspiraciones lejanas la imaginación trascendental busca la salida humana ${ }^{275}$. La descentración de la perspectiva racionalista del yo completa y obliga, se teme y se desea. Es el paso de la relación amo-esclavo a la comunión en la libertad por un esquema de señales flexibles ${ }^{276}$. La mecanización de los signos y la reflexión conduce al maquinismo desertor de la consciencia ${ }^{277}$. Solamente una existencia comunicada deja de ser traumática y resurge realmente viva, con una virtualidad ilimitada de materia inmemorial que se presta a exégesis múltiples ${ }^{278}$ desde la claridad de la firmeza a la paciencia de la obscuridad que diría Giraudoux ${ }^{279}$.

El hombre tiene por horizonte el «ápeiron», lo indefinido de una vida dada graciosamente que es finita pero también un puro existir viviente ${ }^{280}$ que pide interpretación y sentido concreto, pues «el símbolo da que pensar» ${ }^{281}$. Así hay como una finitud de recibir y una infinitud 'de decir', y 'querer decir' que culmina en el «verbo» ${ }^{282}$ y es recogida después en el discurso filosófico como reminiscencia y expectación orientadora ${ }^{283}$ al descubrirse con una especie de hermenéutica espontánea su dimensión cósmica, onírica y poética ${ }^{284}$.

La opacidad del símbolo encierra su profundidad, se da a la hermenéuti-

271. Citado por J. D. STEWART, «Paul Ricoeur», PhT, 9 (1968) 576.

272. Citado por J. D. STEWART, Ibidem, 577.

273. Citado por J. D. STEWART, Ibidem, 578-579.

274. $H V, 159$.

275. VI, 91.

276. VI, 122, 123.

277. VI, 286.

278. VI, 368.

279. Citado por $V I, 383,384$.

280. VI, 288, 289.

281. $H F, 15$.

282. $H F, 37$.

283. $S M, 11$.

284. $S M, 16$. 
ca y a la reflexión como enigma del hombre y su futuro: El sentido y la transcendencia se hacen transparencia ${ }^{285}$ filosófica para comprenderlo todo al comprenderse a sí mismo desde la plenitud del lenguaje que explicita presupuestos y tematiza su estructura universal por una arquitectónica de la razón ${ }^{286}$. El esfuerzo de Ricoeur se encamina a una gran filosofía del lenguaje que dé cuenta de las múltiples funciones del significar humano y sus implicaciaones ${ }^{287}$. Así como en Nietzsche toda filosofía deviene interpretación, Ricoeur busca la restauración del sentido con la redución de las ilusiones mistificadoras ${ }^{288}$ lo que salvará a la reflexión de su vanidad que habla en ninguna parte, al acoger toda experiencia. La hermenéutica cree en la sabiduría implícita del «lenguaje natural» ${ }^{289}$.

La hermenéutica representa una contestación y una prueba para la reflexión filosófica cuyo primer momento es identificarse con la consciencia inmediata ${ }^{290}$, para ponerla a prueba enseguida al sospechar que el objeto, la consciencia e incluso el «moi» es una función económica del deseo de existir. Tal es la prueba de fuego de la filosofía reflexiva, ya que la económica y la hermenéutica coinciden en los escritos freudianos de metapsicología ${ }^{291}$.

Aunque la energía es irreductible al lenguaje, aquella tiende a representarse por retoños-signos: «La psychanalyse ne se met jamais en face de forces nues, mais toujours de forces en quête d'un sense; c'est ce lien de la force au sens qui fait de la pulsion elle-même une réalité psychique ou, plus exactement, le concept-limite à la frontière de l'organique et du psychique» ${ }^{292}$.

La pulsión es el primer concepto energético y su representación el primer concepto hermenéutico ${ }^{293}$. El análisis del deseo intenta «le retour au discours vrai» según De Waelhens ${ }^{294}$.

La coordinación del lenguaje económico y el lenguaje intencional es la gran cuestión de la epistemología a elaborar por Ricoeur ${ }^{295}$. Es la relación entre lo infra-lingüístico, lo lingüístico y lo supra-lingüístico. Para no alienar la reflexión debe unirse a la explicación topo-económica un trabajo de interpretación ${ }^{296}$.

285. $S M, 23$.

286. $D I, 46,48$.

287. $D I, 13-15$.

288. $D I, 35$.

289. DI, 57.

290. $D I, 62$.

291. DI, 130, 145. F. GomA, Conocer Freud y su obra. Barcelona 1977, 72 y ss.

292. $D I, 153$.

293. DI, 255.

294. Citado en DI, 379.

295. DI, 384.

296. $D I, 416$. 
Aquí se pone en cuestión el estatuto de la 'representación' en una 'antropología concreta': «Une méthode herméneutique, couplée à la reflexion, va beaucoup plus loin qu'une méthode eidétique comme celle que je practiquais alors: la dépendance du Cogito à la position du désir n'est pas directement saisie sur l'experience immédiate, mais interprétée par une autre conscience, sur les signes en apparence insensés offert à l'interlocution; ce n'est aucunement une dépendance ressentie, c'est une dépendance déchiffrée, interprétée à travers les rêves, les fantasmes, les mythes, qui constituent en quelque sorte le discours indirect de cette ténèbre muette. L'enracinement de la réflexion dans la vie n'est lui-même compris dans la conscience réflexive qu'à titre de vérité herméneutique» ${ }^{299}$. De modo similar a cómo la fenomenología de Hegel al descentrar el hogar del sentido engendra una nueva hermenéutica en la que el espíritu es la dialéctica de las figuras ${ }^{298}$.

El deseo como deseo de otra consciencia es verdaderamente el deseo humano. Así, en la dialéctica arqueología-teleología está la solución al conflicto hermenéutico. El símbolo es el momento concreto de esta dialéctica ${ }^{299}$ y la reflexión segunda es la ingenuidad docta en la que la reflexión deviene hermenéutica ${ }^{300}$. Aquí comprender ya no es un modo de conocer sino un modo de ser, el de ese ser que existe al comprender. Antes del sujeto de la teoría del conocimiento está la vida en acción, antes del objeto y la objetividad está el horizonte de la comprensión ${ }^{301}$. El sujeto, en Husserl, se abre a un campo de significación no a la Naturaleza, pero en el primer Husserl acaba en el idealismo.

Sólo la hermenéutica hace revivir la estructura. Donde el estructuralismo pone sólo diferencias y oposiciones, la interpretación pone un fondo simbólico sobredeterminado ${ }^{302}$. Tener en cuenta el estructuralismo es necesario para pasar de la ingenuidad simbólica a la inteligencia hermenéutica ${ }^{303}$ interiorizadora del cosmos que muestra alguna cosa de alguna cosa. Por eso, según Ricoeur: «L'articulation d'une sur l'autre, d'une philosophie réflexive et d'une philosophie herméneutique du 'sens est la tâche le plus urgente aujourd'hui d'un antropologie philosophique» ${ }^{304}$.

Al no coincidir totalmente consigo mismo, el hombre presenta una con-

\footnotetext{
297. $D I, 443$.

298. DI, 447, 448.

299. DI, 476, 477.

300. DI, 478.

301. DI, 12, 13.

302. $D I, 88$.

303. CI, 63.

304. CI, 143, 144.
} 
centración sobre sí y una expansión al mundo. Por eso también necesitamos apropiarnos lo que somos en las expresiones múltiples de nuestro deseo de ser. Hay una objetivación del acto puro, y una simbolización del deseo natural. Por ello la realidad nos aparece como texto a descifrar: «Pour employer un autre langage, qui n'est pas celui de Nabert, mais que son oeuvre encourage: parce que la réflexion n'est pas une intuition de soi par soi, elle peut être, elle doit être une herméneutique» ${ }^{305}$.

Para Ricoeur la emergencia del ser, en el último Heidegger, es a nivel del lenguaje: "C'est dire que l'émergence du Dasein, en tant que tel, et celle du langage, en tant que parole, constituent un seul et même problème»» ${ }^{306}$. El «yo soy» se convierte en tema de una descripción intuitiva, pero sobre todo de una hermenéutica a partir del 'ser-en-el-mundo' y su qui. Ahora bien, ese qui se nos dice en la libertad, en último extremo, para la muerte, y esta vida se presenta al poeta y al filósofo en el segundo Heidegger como la potencia total del lenguaje que «funda el poder del hombre y de su lenguaje» ${ }^{307}$. Así el Dasein auténtico «préserve la force de l'être par le moyen de la force du mot» ${ }^{308}$.

Ahora bien, la antropología filosófica, para ser completa y no-subjetivista debe recoger tanto la semiología dispersa de las ciencias humanas como la semántica del deseo, tarea conjunta que corresponde a la hermenéutica ${ }^{309}$. Los signos son «el medio gracias al cual un existente ser humano busca situarse, proyectarse y comprenderse» ${ }^{310}$. Es lo que llama Ricoeur, la 'reflexión concreta'. El lenguaje, por tanto, es un modo de ser en el ser.

Por eso hoy la 'antropología filosófica, por medio de la lingüística, la semiología y el psicoanálisis, a partir de la estructura del ser-en-el-mundo, cruza por el sentimiento de la situación, la proyección de las posibilidades concretas y la comprensión, y avanza hacia el problema de la interpretación y el lenguaje: «Ainsi, l'herméneutique philosophique doit montrer comment l'interprétation elle-même advient à l'être au monde. Il y a d'abord l'être au monde, puis le comprende, puis l'interpréter, puis le dire. Le caractére circulaire de cet itinéraire ne doit pas nous arrêter» ${ }^{311}$.

Tal es la superación del solipsismo, el subjetivismo y el idealismo: «...une philosophie réflexive qui, ayant entièrement assumé les corrections et les instructions de la psychanalyse et de la sémiologie, prend la voie longue et de-

\footnotetext{
305. CI, 221.

306. $C I, 223$.

307. CI, 232.

308. CI, 232.

309. $C I, 258-260$.

310. $C I, 260$.

311. CI, 261.
} 
tournée d'unie interprétation des signes, privés et publics, psychiques et culturels, où viennent s'exprimer et expliciter le desir d'être et l'effort pour exister qui nous constituent» ${ }^{312}$.

La hermenéutica de los símbolos se abre camino entre el historicismo ingenuo del fundamentalismo, y el moralismo exangüe del racionalismo ${ }^{313}, \mathrm{y}$ responde a la situación filosófica y cultural que ante las dificultades y el problema de encontrar un punto de partida en filosofía, recurre a lo arcaico, lo nocturno, lo imaginario, etc. Aquí se parte del pleno del lenguaje cuyo problema no es tanto el comienzo como la memoria ${ }^{314}$ del pensamiento 'puesto' y pensante. Por una parte todo ha sido dado en enigma antes de la filosofía, por otra, ésta se nutre de aquello y busca un comienzo, un orden, una especie de código de interpretación con un cierto apetito de sistema ${ }^{315}$.

Tal espíritu de sistema pasa por tres etapas: La primera o fenomenológica insiste en presentar la coherencia del símbolo; luego se pasa a un análisis comparativista, para desembocar en el momento propiamente hermenéutico que incide en la unión de la donación del sentido dado por el símbolo y la iniciativa inteligente del descifrar; como además en ello se implica la vida sobreviene el 'círculo hermenéutico' que no es un círculo vicioso, «sino un círculo viviente y estimulante» ${ }^{316}$.

Por la hermenéutica el pensamiento humano se configura a la vez como ligado (comprometido), encarnado (liée) y libre ${ }^{317}$. La hermenéutica explicita la precomprensión que anima la interpretación. Aclarar la función de los símbolos en la reflexión filosófica es el problema hermenéutico propiamente dicho. Todo simbolismo es prisionero de una cultura, por eso necesita interpretación: «Opacité, contingence culturelle, dépendance à l'égard d'un déciffrage problématique: telles sont les trois déficiences du symbolisme, face à l'idéal de clarté, de necessité et de scientificité de la réflexion» ${ }^{318}$. Se trata de una reanunciación del hombre y del mundo que constituye propiamente una nueva antropogénesis, la instauración de la existencia humana desde un lugar del que ella no dispone pero «qui lui est annoncé symboliquemente dans une parole

312. $C I, 262$.

313. $C I, 280$.

314. E. TRIAS, La memoria perdida de las cosas. Madrid 1978.

315. CI, 292. U. ECo, La estructura ausente. Barcelona 1978, 145: La semiótica procede como si existiera una Estructura general «pero para poderlo hacer ha de admitir que esta Estructura general es una pura hipótesis operativa y que cada vez que se describe una estructura se ha producido algo en el univerșo de la comunicación que hace que ya no sea enteramente plausible».

316. $C I, 294$.

317. $C I, 296$.

318. $C I, 313$. 
fondatrice» ${ }^{319}$. Ahora hermenéutica no es principalmente de la escritura como en Dilthey, sino que se trata principalmente de la relación de la escritura o código a la palabra y de esta al acontecimiento y al sentido. Sin esta articulación dialéctica de hermenéutica y expresión lo estructural se convierte en un formalismo empobrecedor que pasa por alto la dialéctica entre praxis y estructura ${ }^{320}$. Es preciso reconciliar hermenéutica y estructuralismo pero de un modo no ecléctico y eliminativo de uno de los polos; lo que el símbolo da a semejanza del signo a nivel de contenido no puede desaparecer en la estructura como algo puramente residual sin importancia, eso sería el modo de mantener oculto un dualismo, y no se trata de dividir: «C'est pourquoi l'intelligence structurale ne va jamais sans un degré d'intelligence herméneutique, même si celle-ci n'est pas thématisée») ${ }^{321}$.

El estructuralismo somete el parecido al contraste, la semántica a la sintaxis ${ }^{322}$, pero esta opción no es excesivamente evidente, $y$, por otra parte, el estructuralismo (Lévi-Strauss en este caso) «aussi bien est-ce lui qui parle de métaphore ${ }^{323}$. Ricoeur quiere insistir en la antigua unidad entrè 'logos' y 'ser' para no someter la realidad principalmente a lo formal ${ }^{324}$, aunque lo formal sea necesario. La metáfora en su uso vivo es una estrategía eurística de transacción de contextos ${ }^{325}$, como acontecimiento de sentido con un estatuto lógico capaz de superar la equivocidad ${ }^{326}$. Así, la metáfora es una confusión categorial premeditada y calculada que de acuerdo con Nelson Goodmann supóne un idilio entre un predicado con un pasado y un objeto que cede todo $n-$ ro con protesta ${ }^{327}$.

No se trata solamente de un nivel semántico de frase, sino de un discurso que refiere al mundo ${ }^{328}$. La hermenéutica trata textos, no frases, y los textos no se refieren sólo a una unidad de discurso, sino también a las obras ${ }^{329}$. En este sentido la suspensión de la referencia inmediata en el poema solamente es la condición previa para otra referencią más profunda ${ }^{330}$ : Palabra y mundo, y

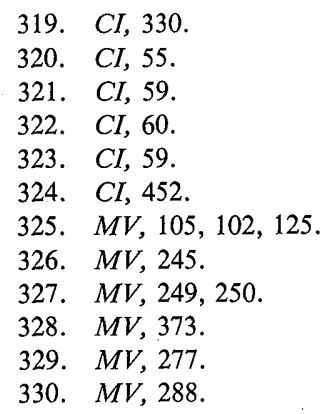


trabajo y mundo se responden mutuamente, pero entre descripción y redescripción hay una eurística de modelos ${ }^{331}$.

La metáfora es al lenguaje poético lo que es el modelo al lenguaje científico, cuando se afirma un modelo se produce una redescripción ${ }^{332}$. Por eso dice Mary Hesse en línea con Max Black que el modelo es un instrumento de redescripción, va más allá de lo meramente observable con la metáfora y en ese sentido pertenece más al lenguaje de la invención que al de la comprobación o prueba ${ }^{333}$; se trata más de una red de enunciados que de una simple imagen, tiene que ver con lo ontológico y rompe la dualidad interior-exterior ${ }^{334}$.

Lo oculto de la filosofía anticipa lo no-dicho de la metáfora, y aquí se trata de investigar la vivificación mutua del discurso filosófico y el discurso poético ${ }^{335}$, a partir de la idea de Heidegger de que toda metafórica es dentro de una metafísica; pero no se trata de un mero explicitar lo que estaría completamente preparado de inmediato en la metafórica, sino de un ser y no-ser dinámico que sugiere la necesidad y ofrece el material de una aclaración interior y necesaria ${ }^{336}$ con una circularidad entre dirección de universalización y dirección de concretización. Una labor siempre inacabada de lo más conocido a lo menos conocido que ejerce cierta atracción y de algún modo siempre está presente, con una energía que opera el arrancarse hacia otro mundo y realizar una trasferencia ${ }^{337}$.

La interpretación es un discurso que actúa en la intersección de dos movimientos, el metafórico y el especulativo ${ }^{338}$. Se trata de una referencia en tensión, la dialéctica del ser como existencial y como relación, como potencialidad y como actividad de forma correlativa y circular, en profunda colaboración y con un gran abismo entre ambos cual reina entre pensamiento y poesía, al decir de Heidegger ${ }^{339}$, según un alejamiento y una reconquista del discurso, también del ser. Por eso la comprensión de un texto hace saltar nuestra situación y nos presenta un nuevo mundo en la trama de la historia y no sólo en el lenguaje ${ }^{340}$.

La hermenéutica es la función interpretativa de los símbolos en la economía de la reflexión filosófica del mundo, y la situación, para resucitarlo ${ }^{341}$.

331. $M V, 297$.

332. $M V, 301,301$.

333. $M V, 305$.

334. $M V, 309-310$.

335. $M V, 325,257$.

336. $M V, 375,376$.

337. $M V, 378$.

338. $M V, 383$.

339. $M V, 398$.

340. P. RiCOEUR, «Evénement», $A F, 2$ (1971) 26.

341. P. Ricoeur, «Evénement et sens dans le discours», M. Philibert, Paul Ricoeur, 185. 
La consciencia, finalmente está expuesta a la eficacia de la historia y es muy difícil tomar distancia de prejuicios y precomprensiones, de intereses creados (Marx, Habermas) y es preciso buscar una comunicación liberadora sin límites ni trabas; en esto Ricoeur va por el camino de Habermas ${ }^{342}$.

Domingo NATAL

342. P. Ricoeur, «Science et», RPhL, 72 (1974). P. Ricoeur, Hermeneutics and human sciences. London 1981. J. B. ThOMPSON, Critical hermeneutics. A study in the thought of Paul Ricoeur and Jürgen̉ Habermas. London 1981. 